\title{
Remote vascular interventional surgery robotics: a literature review
}

\author{
Yang Zhao ${ }^{1}$, Ziyang $\mathrm{Mei}^{1 \wedge}$, Xiaoxiao Luo ${ }^{1}$, Jingsong $\mathrm{Mao}^{2}$, Qingliang Zhao ${ }^{3}$, Gang Liu $^{3}$, Dezhi Wu ${ }^{1}$ \\ ${ }^{1}$ Department of Mechanical \& Electrical Engineering, Xiamen University, Xiamen, China; ${ }^{2}$ Department of Radiology, Xiang'an Hospital of \\ Xiamen University, Xiamen, China; ${ }^{3}$ State Key Laboratory of Molecular Vaccinology and Molecular Diagnostics Center for Molecular Imaging and \\ Translational Medicine, School of Public Health, Xiamen University, Xiamen, China
}

Contributions: (I) Conception and design: Y Zhao, Z Mei, D Wu; (II) Administrative support: G Liu, J Mao, Q Zhao; (III) Provision of study materials or patients: G Liu, J Mao; (IV) Collection and assembly of data: Z Mei, X Luo; (V) Data analysis and interpretation: Y Zhao, Z Mei; (VI) Manuscript writing: All authors; (VII) Final approval of manuscript: All authors.

Correspondence to: Dezhi Wu. Department of Mechanical \& Electrical Engineering, Xiamen University, Xiamen 361102, China. Email: wdz@xmu.edu.cn.

\begin{abstract}
Vascular interventional doctors are exposed to radiation hazards during surgery and endure high work intensity. Remote vascular interventional surgery robotics is a hot research field, in which researchers aim to not only protect the health of interventional doctors, but to also improve surgical accuracy and efficiency. However, the current vascular interventional robots have numerous shortcomings, such as poor haptic feedback, few compatible surgeries and instruments, and cumbersome maintenance and operational procedures. Nevertheless, vascular interventional surgery combined with robotics provides more cuttingedge directions, such as Internet remote surgery combined with 5G network technology and the application of artificial intelligence in surgical procedures. To summarize the developmental status and key technical points of intravascular interventional surgical robotics research, we performed a systematic literature search to retrieve original articles related to remote vascular interventional surgery robotics published up to December 2020. This review, which includes 113 articles published in English, introduces the mechanical and structural characteristics of various aspects of vascular interventional surgical robotics, discusses the current key features of vascular interventional surgical robotics in force sensing, haptic feedback, and control methods, and summarizes current frontiers in autonomous surgery, long-distance robotic telesurgery, and magnetic resonance imaging (MRI)-compatible structures. On the basis of summarizing the current research status of remote vascular interventional surgery robotics, we aim to propose a variety of prospects for future robotic systems.
\end{abstract}

Keywords: Haptic feedback; medical robotics; vascular interventional surgery

Submitted Aug 09, 2021. Accepted for publication Dec 22, 2021; Published online: 13 Jan 2022.

doi: $10.21037 /$ qims-21-792

View this article at: https://dx.doi.org/10.21037/qims-21-792

$\wedge$ ORCID: 0000-0002-5487-661X. 


\section{Introduction}

Interventional radiology has developed over the last several decades, becoming one of the three main effective therapies, alongside internal medicine and surgery (1). The benefits of interventional radiology are both extensive and beyond dispute. However, the effects of radiation cause concern for patients and interventional radiologists alike. To limit the occupational radiation dose to an acceptable level, radiologists usually use personal protective equipment, such as aprons, thyroid shields, eyewear, and gloves (2). However, this equipment can be heavy and burdensome for radiologists when performing interventional surgery. Hence, interventional surgeons face two major health risks: fluorescent radiation and musculoskeletal strain (3).

To protect radiologists and surgeons from potential health problems caused by fluoroscopy radiation and to minimize patient radiation doses, many institutions have been working in recent decades to develop robotic systems aimed at precisely steering and positioning interventional tools for catheter-based interventional surgeries, such as guidewires, microcatheters, balloons, and stents. These robotic systems are intended to shorten procedural times and reduce patient exposure to contrast agents and radiation, while allowing operators to perform surgery using a remote console behind a radiation shield. The main advantages of using robotic technology are the increased levels of speed, precision, reproducibility, and endurance compared with human performance. Robotic technology has been used in medicine since the mid-1990s, primarily in surgery and radiation therapy (4).

The development of vascular interventional surgical robotics has occurred over many years, but has been complicated by challenging therapeutic methods and surgical procedures, as well as the various types of surgical equipment involved. Vascular interventional surgery robots are commonly designed for angioplasty, vascular embolization, or radiofrequency ablation. The interventional instruments operated by surgical robots also vary depending on the surgical scenario (5-8). Related commercial products have been certified and employed for clinical use in various fields. According to clinical reports, the application of vascular interventional robots has significantly reduced the amount of radiation exposure experienced by interventional doctors and reduced their work intensity (9). The high-precision manipulation characteristics of robotic systems shorten operation times and greatly increase surgical success rates.
The use of robots for vascular interventional surgery has been proposed over many years, and a large number of mature systems are commercially available at present. However, the robotic systems currently used in vascular interventional surgery have the following five disadvantages: (I) the steps for disinfecting, installing, and maintaining vascular interventional surgical robots are cumbersome, which increases their cost of use; (II) vascular interventional surgery is a complicated procedure, and the situation differs greatly for each operation. However, vascular interventional surgical robots have limited functions, poor flexibility, and cannot cover all surgical needs; (III) many types of surgical instruments exist for vascular interventional surgery. However, the existing robotic systems are compatible with only a limited range of catheter guidewires, and, in some cases, a dedicated catheter guidewire for the robot must be used. Moreover, there is poor compatibility with interventional devices; (IV) when manual interventional surgery is performed, experienced interventional doctors often rely on "feel"; remote interventional surgical robots cannot reproduce the haptic perception of a physician; (V) the manipulation of interventional surgical robots is performed entirely by humans, placing high technical demands on operators and rarely demonstrating autonomy and intelligence.

This review begins with a brief overview of vascular interventional surgery before discussing the structural design of interventional surgery robots that have been developed as well as existing research institutions and commercial systems. The key features of vascular interventional surgery robot technology and the frontiers that are currently being developed are then discussed.

We present the following article in accordance with the Narrative Review reporting checklist (available at https://qims. amegroups.com/article/view/10.21037/qims-21-792/rc) (10).

\section{Methods}

A systematic literature search of the Web of Science, IEEE Xplore, Wiley Online Library, Science Direct and Springer Link databases was performed. Key search words included vascular interventional, guidewire/catheter, and robot/ robotics. In addition to articles about robots, review articles on vascular interventional procedures were also searched for and included. Publication years for articles ranged from 1997 to 2020. After sorting through the articles, 113 English-language articles were manually selected. 


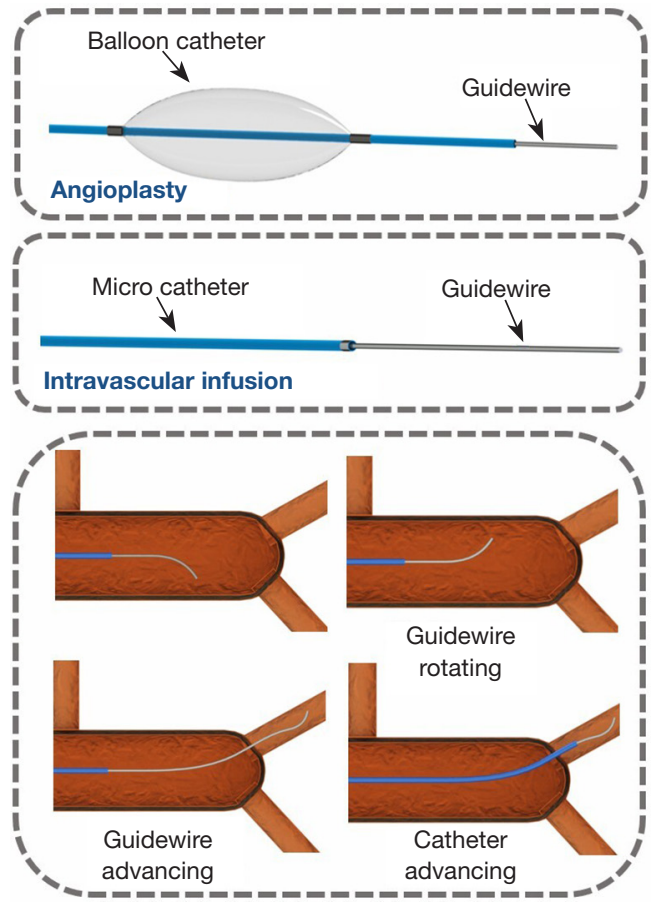

Figure 1 Instruments for angioplasty and intravascular infusion. The main difference between surgical robots designed for angioplasty and intravascular infusion relates to the operation of the interventional instrument. However, both robots use a guidewire to guide the catheter to the desired location.

\section{Structures of vascular interventional robots}

Interventional surgery robotic systems can generally be divided according to their field of application into general vascular interventional robots and electrophysiological interventional therapy robots. General vascular interventional therapy includes angioplasty and intravascular infusion. Electrophysiological interventional therapy includes interventional radiofrequency ablation. These two types of interventional surgery are differed considerably in terms of treatment methods, treatment purposes, and interventional instruments. As a result, the structures of the surgical robots used in these two types of surgery are also very different.

There are many different functions and features of interventional surgical robotic systems. The basic drive functions of interventional devices are first-line requirements and include the multi-degree-of-freedom (DOF) drives for multi-devices with their safety measures. The secondary functions that are implemented include the auxiliary functions of surgical procedures, such as fast loading and unloading designs, syringe pump connections, and compatibility with different surgeries and instruments. The former guarantees the basic functioning of the robotic system, while the latter improve its efficiencies of use, making doctors more willing to use robots in actual operations.

\section{General vascular interventional surgeries}

General vascular interventional surgeries within interventional robotics can be divided into angioplasty and intravascular infusion (Figure 1).

In angioplasty, the balloon catheter is directed to the designated location before the balloon is inflated and deployed. Percutaneous coronary intervention (PCI) is a typical application of angioplasty. The goal of intravascular infusion is to deliver the microcatheter to the designated location and then to place the drug in the designated location through the microcatheter. Transarterial chemoembolization (TACE) is a typical application of intravascular infusion. The main difference between surgical robots designed for angioplasty and for intravascular infusion relates to the manipulation of the interventional instruments. Surgical robots designed for angioplasty need to manipulate the balloon catheter and guidewire, whereas those designed for intravascular infusion need to manipulate the microcatheter and guidewire. The balloon catheter driver of the angioplasty robot is often arranged on the side of the central axis, while the catheter driver of the intravascular infusion surgery robot is often arranged on the central axis.

Guo and colleagues at the Beijing Institute of Technology and Kagawa University have designed multiple interventional surgery robotic systems (Figure 2). Their first-generation system uses a friction wheel mechanism to deliver the interventional device. This generation of robots can only support the two-DOF motion of a single device (11). The second-generation system uses a linear slide to deliver the device. It applies a wealth of forcesensing functions to improve the surgical accuracy (12). The third-generation system uses two sets of linear slides simultaneously. In addition to having abundant forcesensing functions, it can also achieve co-delivery of the interventional guidewire and catheter. This generation of the system outperforms human surgeons $(13,14)$. Based on Guo's third-generation system, Nan et al. of the Beijing Institute of Technology developed the Luban interventional surgery robot system, and completed China's first robotassisted whole-brain angiography in 2020 (15). The 


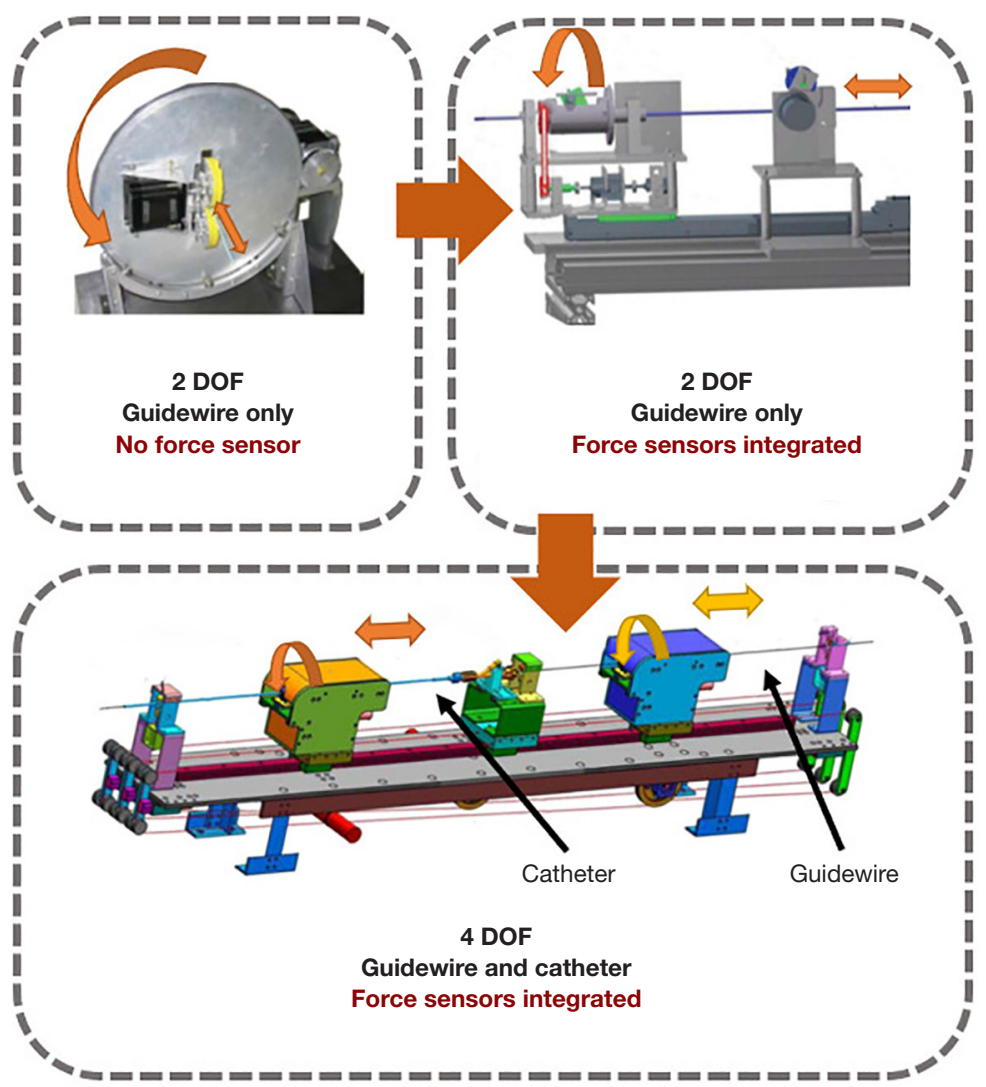

Figure 2 Three generations designed by Guo et al. With surgical robot design iterations from generation to generation, the robots have integrated richer sensing functions and control of more surgical devices simultaneously, with a more compact and reliable mechanical design.

conduction of human experiments imposes extremely high requirements for the functional integrity and safety of the robot, and Guo's linear, platform-based, structural design can meet these requirements. However, such a structure imposes a stroke limit on delivery and is too large, occupying too much space in the operating room.

The models and specifications of guidewires and catheters for interventional surgery are extremely diverse. It is important that they are compatible with as many types of interventional devices as possible. Wang et al. of Shanghai Jiao Tong University designed a novel, universal, endovascular surgical robot (16). This robotic system, which comprises 4 manipulators with 12 degrees of freedom, is potentially compatible with various interventional instruments on the market which are designed to complete a variety of surgical procedures (Figure 3). However, its linear platform-based structure imposes the same problem as Guo's design with respect to stroke limit and robot size. Moreover, the rotation angle of the catheter guidewire is limited, making it impossible to achieve a full $360^{\circ}$ rotation. Although related research is still in the exploratory stage and there is significant progress to be made before any practical application in the human body can be considered, this multi-functional and multi-compatible design is extremely meaningful.

Whereas doctors often manipulate the delivery and rotation of interventional guidewire with one pair of fingers, interventional surgical robots often divide delivery and rotation into different modules to complete the task. Owing to the design of the friction wheel arrangement, only one pair of friction wheels is required to simultaneously achieve the rotation and delivery of the guidewire. This design is extremely similar to the actual manual operating technique of a doctor, and greatly reduces the volume of the surgical robot. Such a design appeared in a bionic interventional surgery robot designed by Bian et al. at the Institute of Automation of the Chinese Academy of Sciences (Figure 4A) (17) and Hansen's Magellan system (Hansen Medical, Mountain 


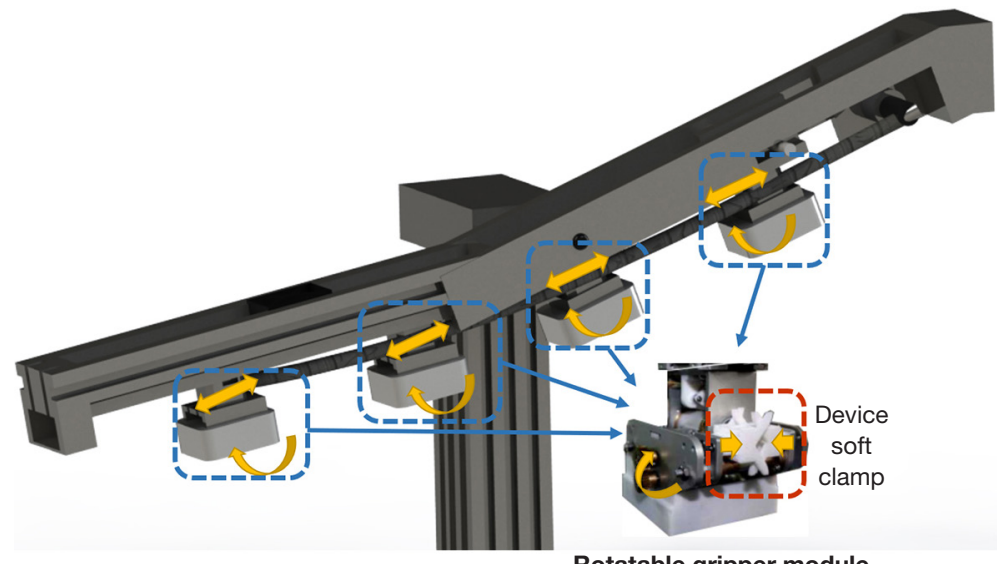

Figure 3 Universal endovascular robot designed by Wang et al. Four independent grippers (in the red-dotted frame in the picture) are installed on a linear platform. Each gripper can move linearly along the platform and rotate within a certain range. Many complex surgical operations can be performed through the combined movement of different grippers. The device clamp of each gripper (in the blue-dotted frames in the picture) is made of a soft material, which can hold interventional instruments of any shape.
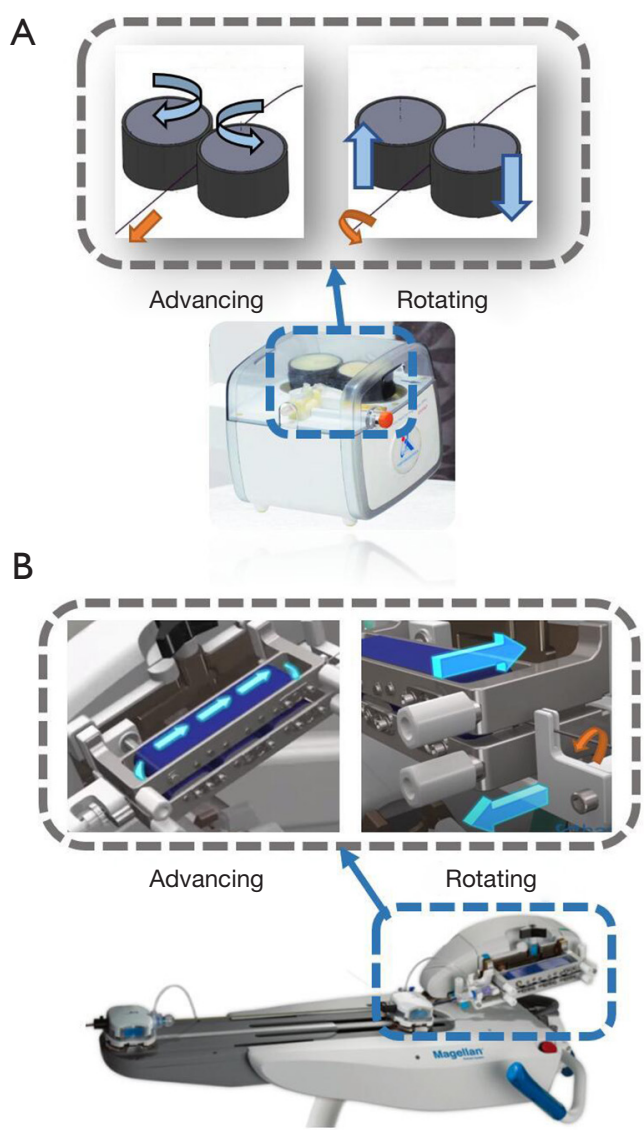

Figure 4 Guidewire manipulators based on friction wheels. (A) Manipulator designed by Bian et al.; (B) manipulator from Hansen Medical (Mountain View, CA, USA). The circumferential rotation of the friction wheel drives the guidewire to move forward or backward, and the axial staggered movement between friction wheels drives the guidewire to rotate. This design uses only a pair of friction wheels to achieve two types of movement of the guidewire; not only is there no stroke restriction on delivery, but the structure is also smaller. 


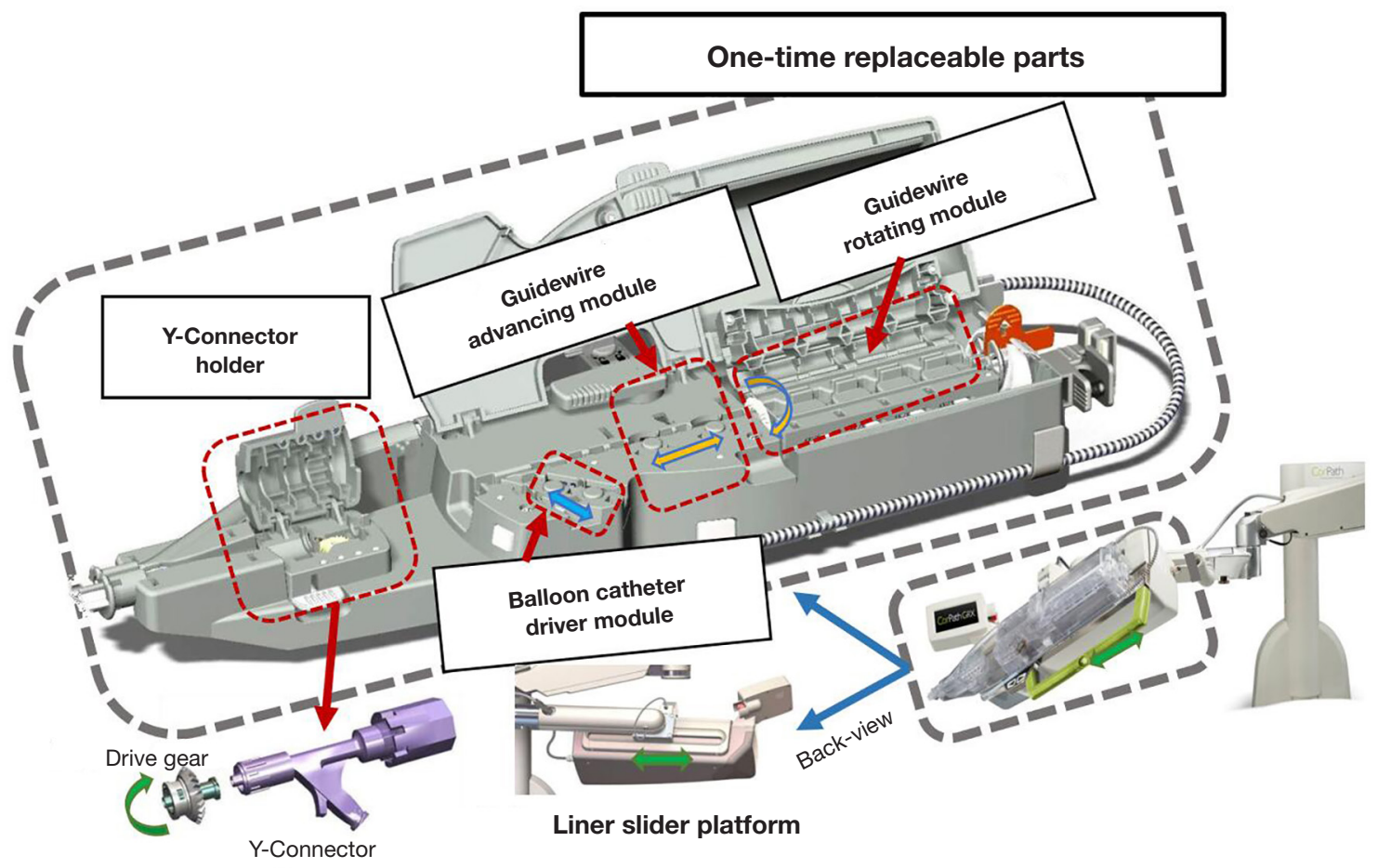

Figure 5 Commercial robotic system CorPath GRX (Corindus Inc., Waltham, USA). The system uses multiple sets of friction wheel mechanisms to deliver the guidewire and the balloon catheter, while using gear sets to drive the rotation of the guidewire and the switch of the Y-connector. For hygiene purposes, the parts in direct contact with surgical instruments are disposable and detachable, and the electrical and mechanical parts are completely isolated.

View, CA, USA) (Figure 4B) (18). From a mechanical point of view, the use of friction wheels to drive the catheter or the guidewire has many advantages. First, there is no stroke limit, and the speed of movement of the surgical instrument is faster. Second, the response of the surgical instrument is more sensitive due to the simple transmission structure. Thirdly, the mechanism is small in size.

Beyar et al. of Israel's Haifa Center have developed a surgical robotic system for PCI based on a friction wheel mechanism. This system can simultaneously operate the interventional guidewire and the balloon catheter. The system is highly versatile and has been used to successfully deploy heart stents in 18 patients. This surgical robotic system is also the predecessor of the Corindus CorPath series (Corindus Inc., Waltham, USA) (Figure 5) (19). The principle of the current CorPath GRX robotic system (Corindus Inc., Waltham, USA) in driving interventional instruments is the same as that for the original design. However, one very important difference is that, for the purposes of hygiene, a large part of the structure is disposable and replaceable. The same applies to Robocath's R-One robot system (Robocath Inc., Rouen, France), which is another commercial interventional surgical robot product (20).

\section{Electrophysiology therapies}

Interventional electrophysiological (EP) therapy has a wide range of applications, and can be used to treat atrial fibrillation, lung tumors, liver tumors, and other diseases. An EP catheter is the main instrument used in EP surgery (Figure 6). The head tip of an EP catheter can be flexibly bent. The operation process does not require a guidewire, but occurs under the guidance of the steerable electrophysiological catheter, itself. The ablation instrument installed on the catheter head tip releases a radiofrequency current to treat the target tissue $(6,7)$.

Interventional surgery robots designed for EP therapy mainly manipulate EP catheters. To be compatible with general EP catheters, the interventional EP treatment surgical robotic system currently under development adopts a 3-DOF control design. A common structure provides 


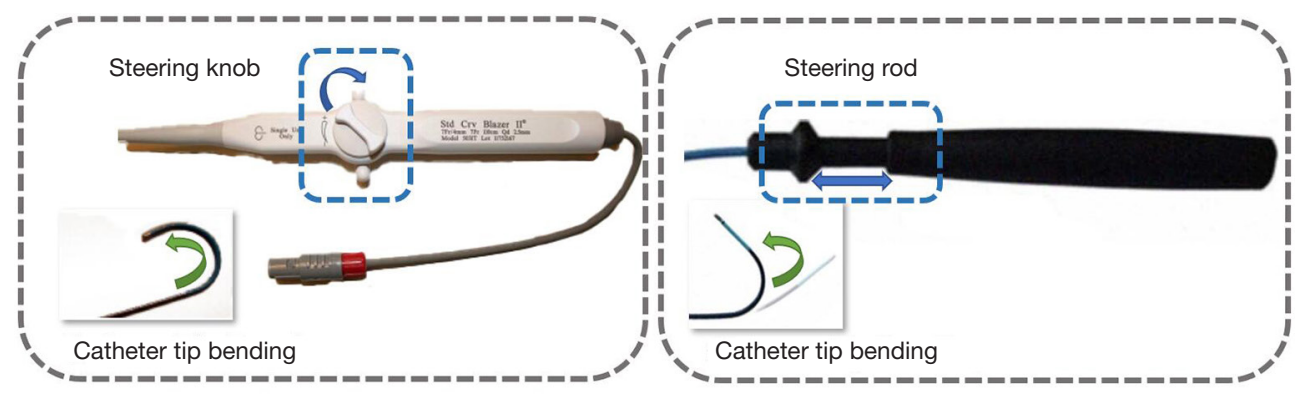

Figure 6 EP catheters. The handle of the EP catheter has a function that allows its tip to bend. EP, electrophysiological.

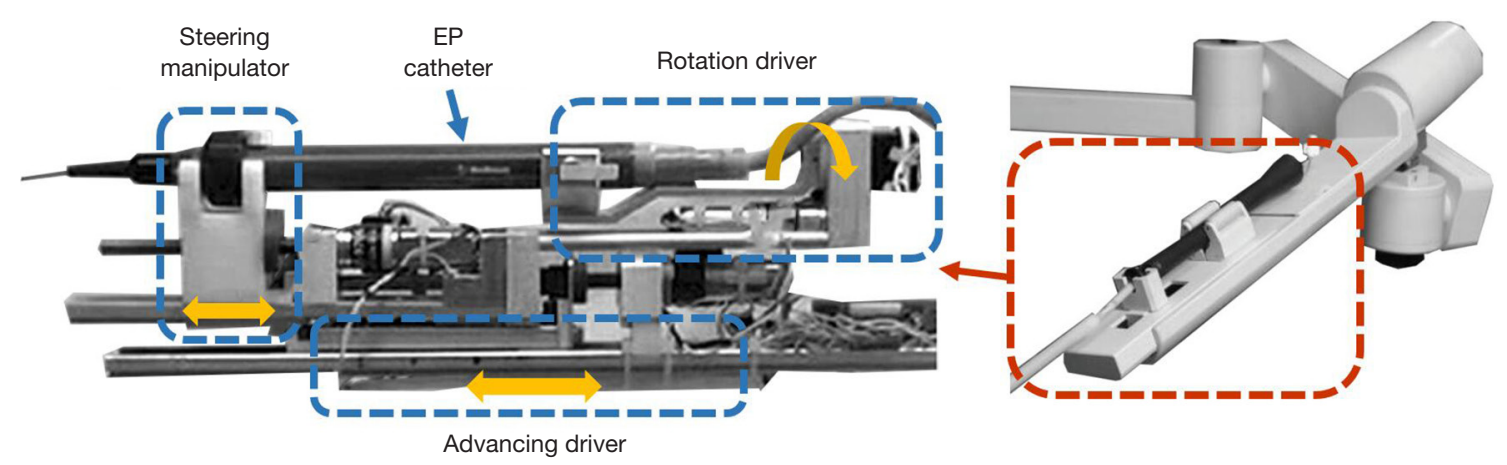

Figure 7 The mechanical structure of the CathROB from Cercenelli et al. The operating handle of an ordinary EP catheter is installed on the robot. This mechanism design achieves the 3-DOF main motion control of the EP handle. The entire mechanical structure is installed on a rotating platform, and the overall rotation of the platform drives the catheter to rotate. The delivery of the catheter is achieved using a linear platform. The steering control of the catheter is achieved by flipping the switch on the catheter handle. EP, electrophysiological; 3-DOF, three-degree-of-freedom.

freedom of delivery using a linear moving platform and clamps, and rotates the EP catheter to achieve rotational freedom. The bending freedom of the EP catheter is controlled by a special operating mechanism.

Cercenelli et al. of the University of Bologna designed a highly compact and versatile remote catheter navigation system named CathROB (21-23), which uses two sets of liner slider structures to achieve full control of the general EP catheter (Figure 7). Park et al. of Korea University (24) and Ganji et al. of the University of Waterloo used similar structures to manipulate EP catheters (25). Their structures featured a liner slider platform, rotation driver, and steering driver to achieve the translation, rotation, and tip-bending motions of EP catheters.

In radiofrequency ablation, it is very important for the EP catheter to point toward the target tissue accurately and stably. The conventional EP catheter distal bend is driven by ropes. Magnetic field-driven EP catheters can achieve higher flexibility and stability than rope-driven mechanism (26). The Genesis remote magnetic navigation (RMN) system (Stereotaxis, St Louis, MO, USA) (Figure 8) uses a specially designed magnetic drive catheter to control the movement of the catheter's front end by altering the external magnetic field (27). Magnetic navigation has the advantages of high flexibility and strong maneuverability.

\section{Key features of vascular interventional robots}

\section{Force sensing}

The forces that can be collected by interventional surgical instruments can be divided into two main types: "distal force", which is the force collected by the tip of the surgical tool located in the body, and "proximal force", which is the force collected by the operating end of the surgical tool outside the body. The distal force is generally composed of the contact force between the surgical tool and the vessel 


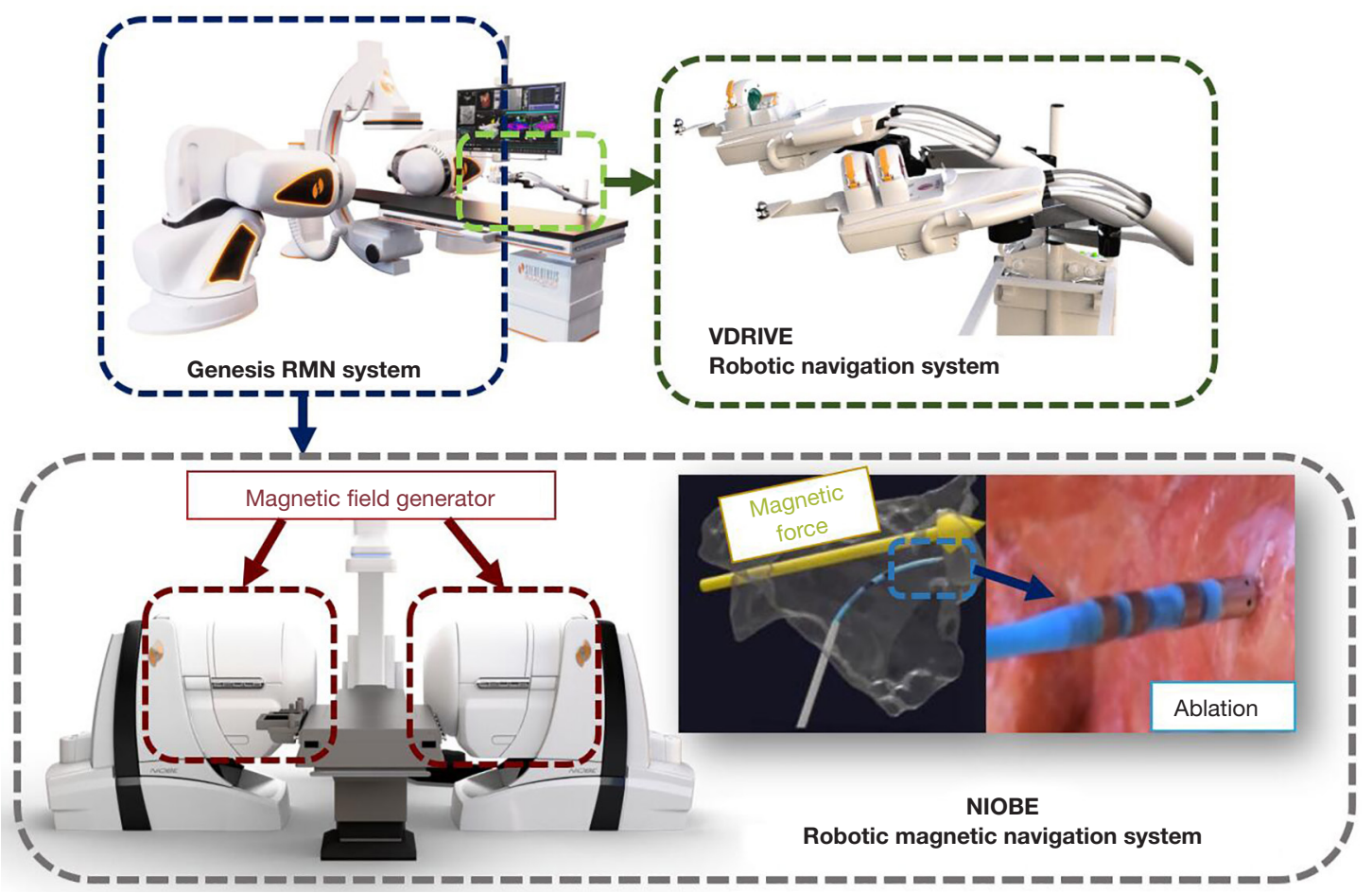

Figure 8 Genesis RMN system (Stereotaxis, St Louis, MO, USA). The catheter navigation system named VDrive coordinates with the magnetic navigation system named Niobe to complete the operation. VDrive achieves the delivery, rotation, and basic steering operations of the catheter, while Niobe further controls the actions of the catheter tip. By changing the external magnetic field with the magnetic field generator, the catheter tip can be accurately and stably pointed toward the target location. RMN, remote magnetic navigation.

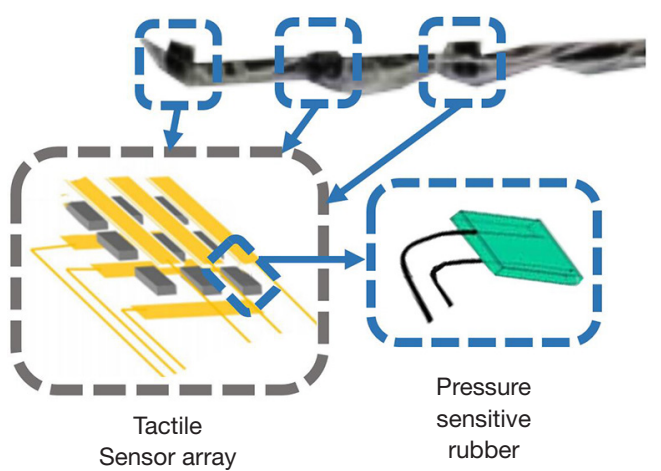

Figure 9 Distal sensors arrangement, according to Guo et al. Pressure-sensitive rubber arrays are configured into sensing units, arranged at the catheter's distal end, and encapsulate the lead. In general, force-sensing units are installed at multiple locations on the catheter to monitor the force conditions at different nodes. wall, while the proximal force is a complex composite force, including contact force, friction force, and the viscous resistance of blood.

The measurement of distal force often requires sensors to be placed on the tip of the interventional instrument. This arrangement can directly measure the force between the interventional device and the blood vessel. Sensitive rubbers, strain gauges, and fiber optic pressure sensors are often used to measure distal force. Guo et al. of Kagawa University have proposed various remote sensor arrangement forms (28-31). For instance, they arranged pressure-sensitive rubbers into tactile sensors and set them at the catheter's distal end (Figure 9). Similar schemes have been employed by other research groups, such as those by Omisore et al. (Shenzhen Institute of Advanced Technology, Chinese Academy of Sciences) (32), Payne et al. (Imperial College of the United Kingdom) (33), and Zhao et al. 


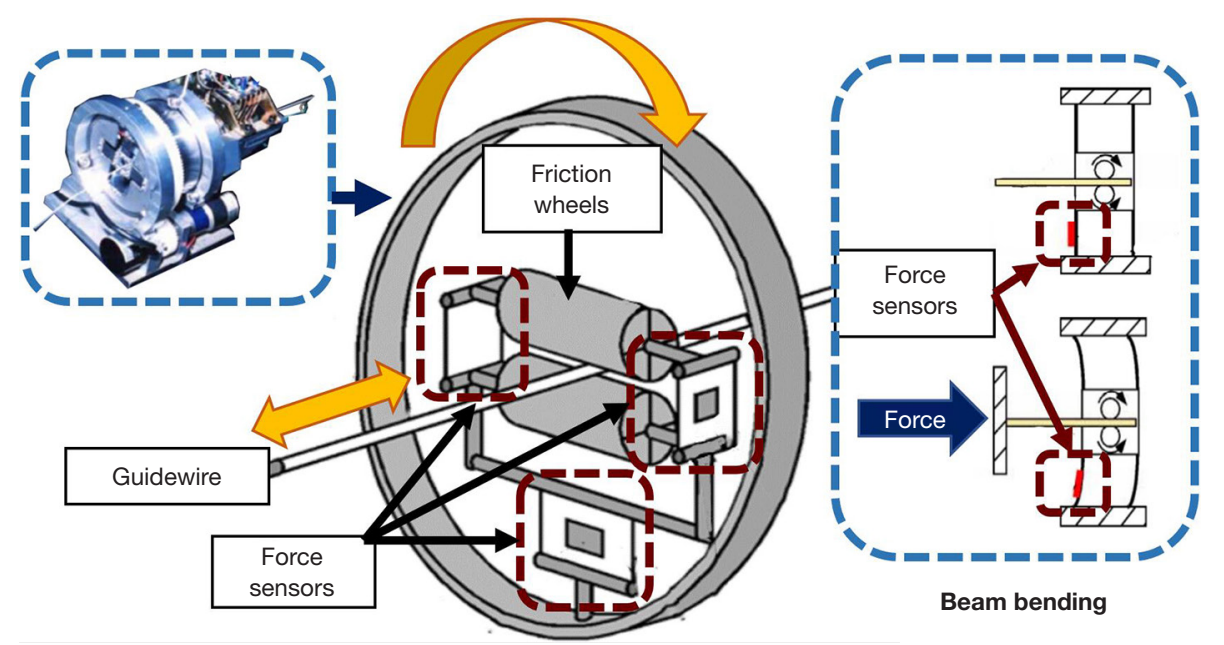

Figure 10 Proximal sensor arrangement by Arai et al. of Nagoya University. Force sensors are set between the transmission components of the robot (red-dashed boxes in the picture). When the guidewire moves, the resistance force will deform the transmission components, and the deformation is detected by the sensor (blue-dashed box on the right).

(Beijing University of Aeronautics and Astronautics) (34).

The current distal sensors of interventional instruments are common in the clinical application of EP treatments. They are mostly arranged in EP catheters. Due to the size of the sensor and the packaging volume of the leads, it is difficult to apply the sensor in general vascular interventional operations, especially in interventional surgery in small blood vessels. In the field of commercial surgical robots, the Sensei surgical robot navigation system (Hansen Medical, Mountain View, CA, USA) integrates a force sensor on the head of its steerable Artisan control catheter (18).

The force that doctors feel during an operation is mostly proximal force. With the interventional surgical robot, it is easier to collect proximal force than it is distal force. Therefore, the measurement of proximal force features most frequently in interventional surgery systems. Setting force sensors between the transmission components of the robot is the most widely used approach, such as in the structures developed by Arai et al. of Nagoya University (Figure 10).

Besides arranging force sensors between the transmission components, Zhou et al. of Xiamen University also attempted to arrange a sensing pipe at the front of the robot, and indirectly judged the magnitude of the resistance through the squeezing that occurred between the interventional device and the sensing pipe (35). Cha et al. of Hanyang University in South Korea (36) and Sankaran et al. of the University of Illinois $(37,38)$ measured the resistance forces based on the input current of the motors. These methods arranged sensors on the outside of the robot, or even used no sensors, to successfully measure the resistance force.

Since the proximal force is a complex resultant force, it can be influenced by the structure of the robot, the shape of the interventional device, and the different arrangement angles of the robot. Therefore, the proximal force has poor reliability, and it needs to be further processed by the algorithm to achieve the related function of force feedback.

\section{Master controllers and haptic feedback}

The master controller is the most important part of humancomputer interaction. From a design perspective, it can be divided into master-slave heterogeneous and master-slave isomorphic interactions. Master-slave heterogeneous refers to the use of a completely different surgical method from the interventional technique; interventional doctors therefore need to undertake more study and experimentation to adapt to its surgical method. In contrast, master-slave isomorphic refers to using roughly the same surgical method as the interventional technique. The interventional doctor can quickly become familiar with the robot's operation and can even reproduce their surgical habits or experience acquired in manual interventional surgery when operating the robot. However, the doctor's experience comes from the manual operation of instruments, and the manual operation of instruments is not necessarily suitable for use in robotic systems. Master-slave heterogeneous manipulators can 


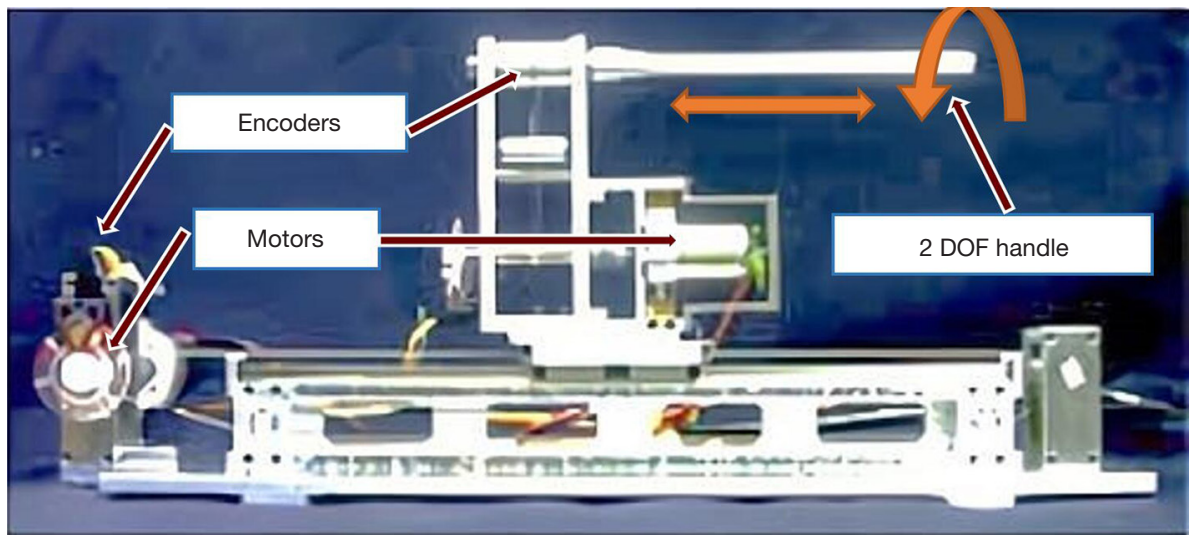

Figure 11 The rod-shaped master controller designed by Tanimoto et al. This controller, which was designed for interventional surgery, is more intuitive than common commercial controllers to use, and the operator controls the rotation or delivery of the interventional instrument by rotating or pushing the handle. Both the rotation and linear movements of the handle are recorded by encoders. At the same time, the internal motor can generate resistance to its handle.

often perform more functions and more comfortable to use than isomorphic manipulators, and conform to ergonomic design. Therefore, a certain balance needs to be established between isomorphism and heterogeneity.

Many research groups have adopted commercial force feedback manipulators such as Novint Falcon (Novint Technologies, Albuquerque, New Mexico, United States) $(39,40)$, Phantom Omni (Sensable Technologies, Woburn, Massachusetts, United States) (11,31), and Geomagic Touch X (3D Systems, Rock Hill, South Carolina, United States) $(13,14)$. Commercial force feedback controllers have rich and stable force feedback functions, and developing a haptic feedback system based on these controllers is simple and efficient. However, their use as master controllers also has an obvious disadvantage: they are general purpose controllers and are not specifically designed for interventional surgery. The experience accumulated by doctors in manual interventional surgery is difficult to apply to such controllers.

To acquire haptic feedback master controllers of the master-slave isomorphism, many research groups have developed their own master controllers. For instance, in 2000, Tanimoto et al. of Nagoya University designed a rod-shaped controller which generates resistance to the doctor's hand through the connected motor (Figure 11) $(41,42)$. Since then, similar structures have been adopted by many research groups, such as Feng et al. at the Institute of Automation of the Chinese Academy of Sciences $(17,43)$, Wang et al. at Shanghai Jiao Tong University $(44,45)$, and Guo et al. at Kagawa University $(12,28,46)$.
Master-slave catheter controllers are another form of master controller design in which the master controller contains a catheter. The robotic system copies the actions from the master catheter to the slave catheter. This form of design ensures that the surgical method of the robot is completely consistent with the actual interventional surgery, which can greatly reduce the doctor's learning threshold and reproduce the interventional doctor's surgical techniques and skills. Early master-slave catheter controllers, such as that of Thakur et al. (47) at The University of Western Ontario, London, only achieved the same motion detection as a master catheter. Some groups later found ways to put resistance on the master-slave catheter. Guo et al. of Kagawa University developed a haptic feedback system based on magnetorheological fluid (29,48-50), and Payne et al. at Imperial College added resistance to a master catheter using a voice coil motor (Figure 12) (33).

\section{Safety strategies}

In the interventional surgery robotic system, using the safest strategy is critical. Dangerous situations that commonly arise during surgery include excessive contact force on the blood vessel wall, excessive deformation of surgical instruments, and incorrect operation by the doctor, any of which can lead to injury. Interventional surgical robotic systems need to avoid such situations as much as possible.

Monitoring and controlling the force of interventional devices is a common force safety strategy. The simplest and most direct method is to measure the force through a force sensor and set a threshold for the feedback signal. Many 


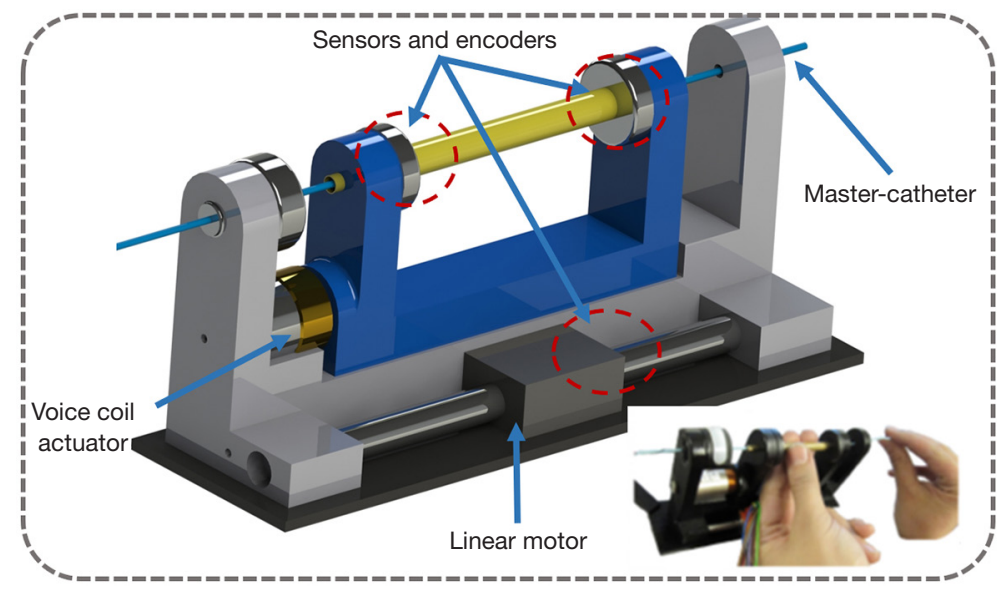

Figure 12 Master-slave catheter controller with haptic feedback. For more intuitive operation, a separate piece of catheter, called the master catheter, is installed on the controller. The controller's built-in sensors and encoders can detect the movement of the master-slave catheter. The controller copies the actions of the master-slave catheter to the catheter under surgery, and outputs resistance forces to the operator through the voice coil actuator and linear motor.

research groups have adopted this approach, including Guo et al. of Kagawa University (31), Cercenelli et al. of the University of Bologna (21), and Zhou et al. of Xiamen University (35). The CorPath GRX system (Corindus Inc., Waltham, USA) also has such a warning function: when excessive force is detected on the interventional device, a warning message is output on the user interface and the system simultaneously prohibits the advancement of the device.

However, setting a threshold for the detected force is a crude approach. The force state of the interventional device is the result of a combination of multiple conditions. It is necessary to accurately identify dangerous situations (Figure 13). Wang et al. of Beijing Institute of Technology proposed a neural network-based force safety method. The neural network intelligently identify whether the state is safe according to the resistance force and torque detected by the sensors in real time, ensuring the safety of the surgery (51). The abnormal deformation of surgical instruments is also extremely dangerous. Dagnino et al. of Imperial College London have introduced image recognition in their surgical robotic system, through which interventional images are identified to track the positional information of the guidewire and the blood vessel wall, and to make safety judgments, applying dynamic constraints (52).

Misoperation by the doctor can result in patient fatality. Shen et al. of Shanghai Jiao Tong University designed an "eccentric spring" algorithm to reduce the error signal input to the controller caused by trembling hands (53).
Also, Xiang et al. used a Kalman filter in their algorithm to eliminate the tremor signal of the doctor's hand (54). Guo et al. of Beijing Institute of Technology used a support vector machine (SVM) to identify whether the operation signal is caused by trembling hands (55). At the same time, they designed an algorithm that could be applied to the master controller using magnetorheological fluid to resist hand tremors (49). Further, to prevent misoperation from causing serious injury to a patient, they also designed a braking device that can stop the movement of the surgical instrument in time when a misoperation is detected (56).

\section{Control methods}

To separate the operator from the radiation environment, the hardware structure of the interventional surgery robotic system is often composed of an upper computer and a lower computer. The upper computer is placed in a noradiation area and connected to the master controllers, while the lower computer is placed in the radiation area and connected to the robot. In such an upper and lower system, the robotic system adopts a master-slave method for control.

Open-loop speed control is a common control method, in which the input signal of the master controller is mapped to the speed space of the surgical robot and converted into the corresponding motor control signal. The mapping space is often divided into multiple sections to reduce excessive speed changes and jittering caused by trembling hands or misoperation. Figure 14 shows the control mapping curves 


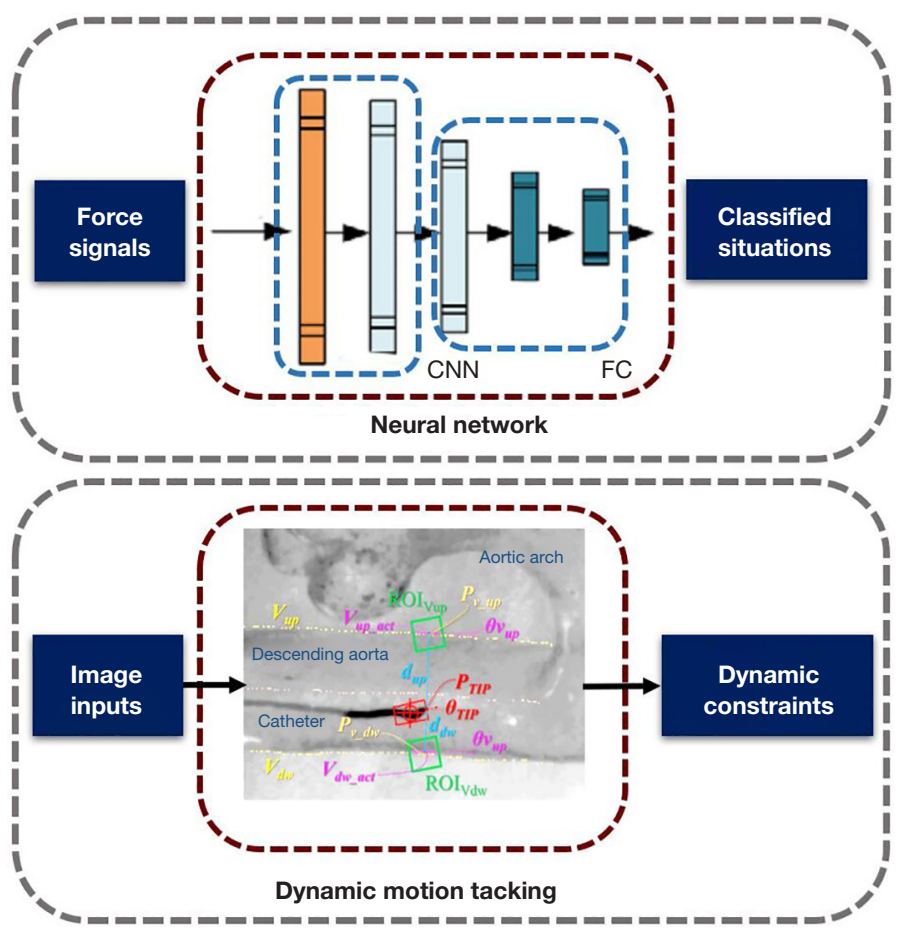

Figure 13 Methods to identify dangerous situations. In addition to the magnitude of the force, the current security situation is also related to the deep fuzzy information in the force signal. Using neural networks to learn this fuzzy information helps the robot to accurately judge the current security situation. By observing the position and posture of the guidewire and the state of the vascular environment through the image, the safety can also be judged.

A

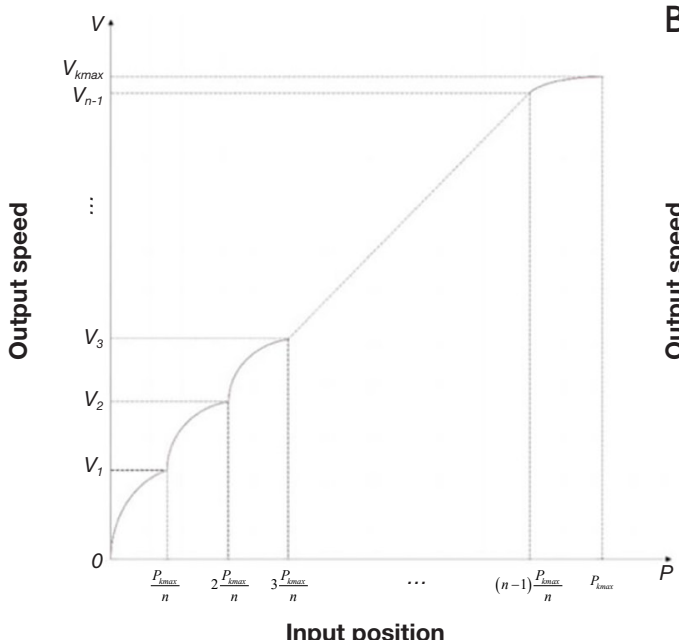

B

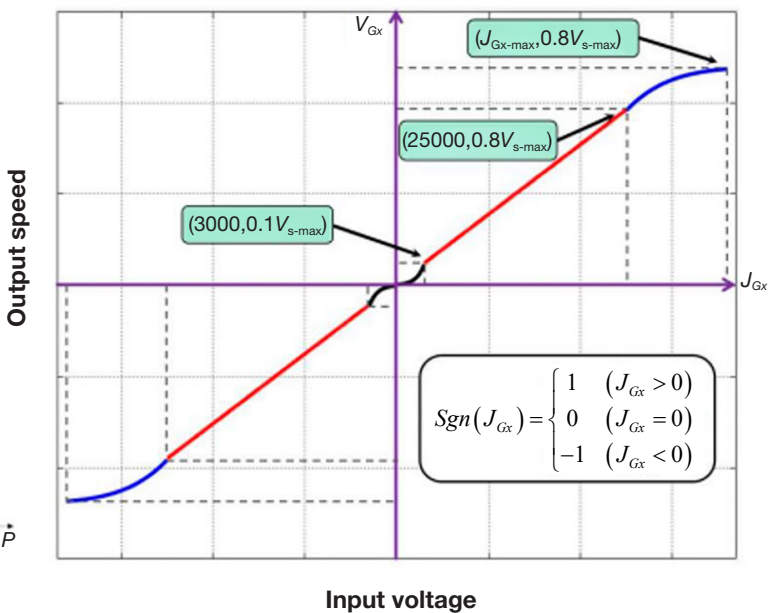

Figure 14 Control-mapping curves. (A) Control-mapping curve of Shen et al. and (B) the mapping curve of Zhou et al. The former mapped the input position of an Omega 3 controller handle to the speed of the surgery robot; the latter mapped the input voltage from a commercial joystick to the speed of the catheter and guidewire. They both set smooth transitions in some sections of the curves to reduce the influence of the operator's trembling hand. 
of Shen et al. of Shanghai Jiao Tong University $(53,57)$ and Zhou et al. of Xiamen University (35). Such open-loop speed control is simple.

If a surgical robotic system is equipped with position or angle sensors, more precise and stable closed-loop control can be achieved. Closed-loop control is more often used in position or angle control; the input signal of the master controller is mapped to the position space of the surgical robot and converted into the corresponding motor control signal. At the same time, the control system compares the feedback position of the sensor to achieve accuracy. Commonly used position sensors include angle encoders, position sensors of linear platforms, and electromagnetic tracking sensors, such as the NDI Aurora (NDI, Waterloo, ON, Canada).

Sometimes the motion of the control object of the surgical robot is complicated, such as the bending of an EP catheter at the front end. In that case, the relationship between the input of the robotic system actuator and the output position of the interventional instrument can be resolved by building a kinematic model $(25,57,58)$. In addition to control methods based on classical control theory, the use of control methods in modern control theory can sometimes improve the control system's performance. For instance, Wang et al. of the University of Hong Kong applied a control method based on optimal control in their interventional surgery robotic system. Their experiments show that the control method's performance based on the optimal control theory is better than that based on the kinematic model (59).

Proportional-integral-derivative (PID) control is the most used feedback control method. It performs proportional, integral, and derivative of the difference between the target value and the measured actual position value, and it combines these control variables to achieve stable tracking of the controlled object. Many research groups have used PID controllers for surgical robot control $(33,47)$. Based on PID control, the setting of fuzzy rules to dynamically adjust the PID controller parameters can realize more sensitive and stable fuzzy adaptive PID control. Wang et al. of Yanshan University applied a fuzzy PID controller in their surgical robotic system, and the fuzzy PID controller showed better performance than the traditional PID controller $(60,61)$.

The control methods for speed, position, force, and other objects are mature and abundant. The closed-loop control method is highly robust, so a rich and stable sensor scheme in a robotic system is extremely important.

\section{Frontiers of vascular interventional robots}

\section{Automation surgeries}

Because actions performed by traditional master-slave interventional surgical robots generally depend on actions input by the operator, the surgical outcome depends on the operator's performance. There are often mistakes in manual operation, which potentially reduce the efficiency of surgery. Human reaction abilities, accuracy, and flexibility are far weaker than those of robotic systems. In the future, autonomous surgery might even replace doctors, thus saving hospital human resources. The goal of autonomous control technology is to enable robotic systems to complete part of a surgical process or even completely take over an operation.

A common method to achieve autonomous delivery is to specify a delivery rule based on the state of the interventional device. Jayender et al. of Weston University proposed an autonomous method that uses machine vision $(58,62)$. Through image recognition of the path of the in vitro model, the robot can autonomously deliver the catheter to the target location. Corindus has introduced a Food and Drug Administration (FDA)-approved guidewire autonomous feature known as "Rotate-on-Retract" (Corindus Inc., Waltham, USA). The function of this feature is to rotate the guidewire whenever it is retracted by the operator, changing the orientation of the guidewire tip in preparation for the next advancement (63).

However, the environment of interventional surgery is highly complicated, and rules set by people can handle only very limited situations. Moreover, many experiences of interventional surgery are vague and difficult to describe with specific rules. Using AI (artificial intelligence) to learn how to operate interventional devices based on the experience of experts or self-exploration is an emerging method (Figure 15). Guo et al. of the Beijing Institute of Technology proposed an intelligent autonomous interventional surgery agent by using neural networks to learn from the operating records of multiple human experts.

In addition to learning from human demonstrations, agents can also learn from self-exploration, in a process referred to as reinforcement learning. Through reinforcement learning, it is even possible to obtain an agent whose ability far exceeds that of human beings. Chi et al. of Imperial College applied reinforcement learning methods to their AI agent. They used the most advanced algorithm in the field of reinforcement learning-proximal policy optimization—and their agent performed better than human 

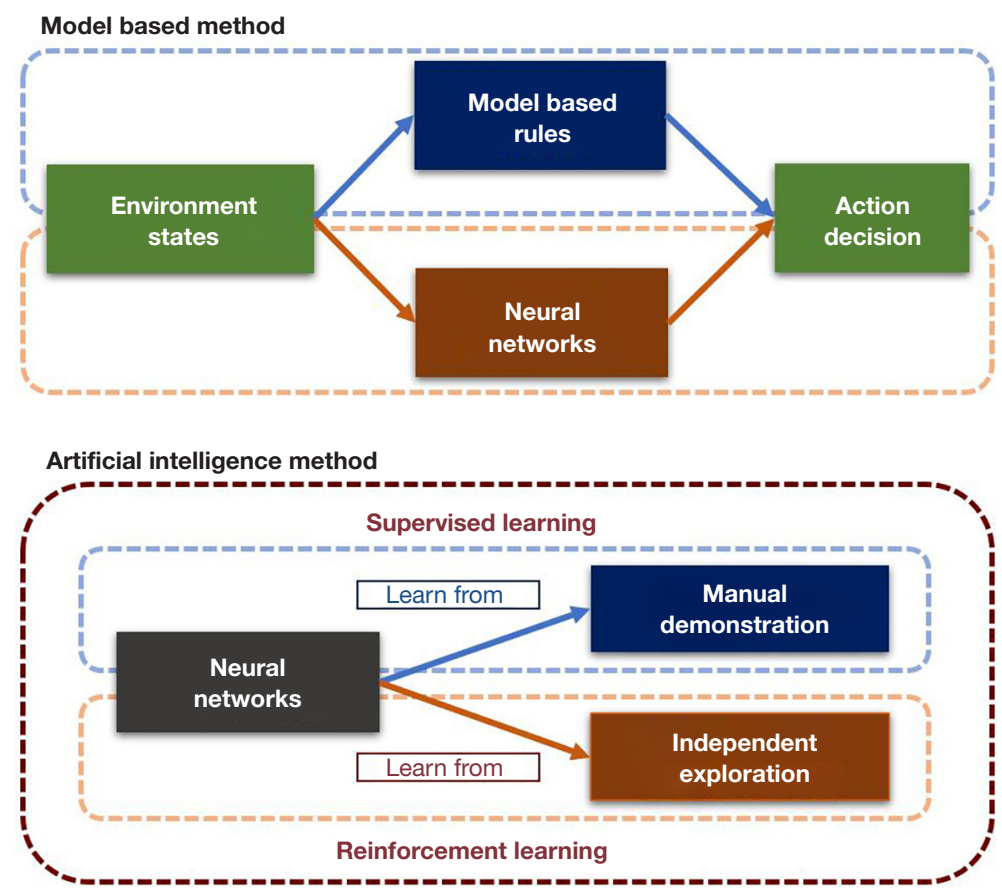

Figure 15 Methods for autonomous delivery. The environment of intravascular surgery is complex, and model-based methods may be difficult to make complex and ambiguous decisions. Artificial intelligence-based methods can learn fuzzy environmental regulations through supervised learning or reinforcement learning and make more complex decisions.

experts in the in vitro models (64). In its application in various fields, reinforcement learning has shown outstanding performances, and autonomous interventional surgery agents based on reinforcement learning appear to be very promising.

In the process of interventional surgery, the information that can be observed from the image is abstract and complex. The surgical operation is difficult and requires an experienced doctor to complete it. It is also difficult to predict sudden situations arising during the operation. The current autonomous delivery methods are all difficult to fully implement in the human body, and more in-depth research is needed.

\section{Robotic telestenting over long geographic distances}

Robotic telestenting over long geographic distances has received increasing attention in recent years. Using remote communication to allow doctors to perform remote operations over long geographic distances, on patients in another location, can help to alleviate the uneven geographical distribution of interventional doctors, optimize human resources, and popularize interventional operations across various regions. Today's Internet technology is very mature, especially the emerging $5 \mathrm{G}$ network technology, which can fully meet the low latency and large data throughput required by Internet surgery.

Guo et al. built a cloud server platform for their surgical robot platform, and verified that the cloud server can fully meet the needs of remote surgery (65). Based on the CorPath GRX surgical robotic system, in 2018, Madder et al. performed the first remote model and in vivo animal interventional experiments, which confirmed the safety and feasibility of remote interventional surgery (Figure 16) (66). In 2020 , they used wired networks and $5 \mathrm{G}$ wireless networks to perform successful remote transcontinental interventional experiments (67).

\section{Magnetic resonance imaging (MRI) compatibility}

The fusion of interventional surgical robots and MRI navigation is the focus of the research direction of several institutions. Since MRI does not rely on the use of fluorescent radiation in the human body, children, pregnant women, and other people who are sensitive to radiation are considered suitable for interventional surgery under MRI. Although the MRI environment does not pose any threat 
to the health of interventional surgeons, the application of surgical robots can still reduce the labor burden on doctors and improve the performance of surgery. In contrast, ferromagnetic and conductive materials are not compatible

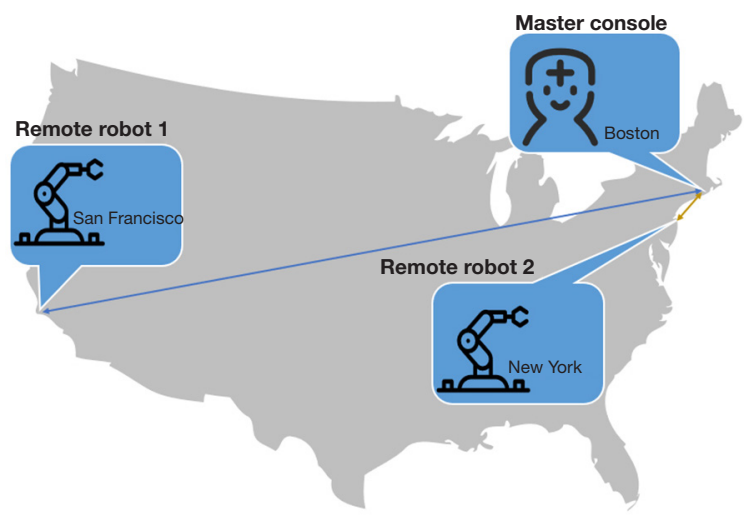

Figure 16 The internet remote experiments of Madder et al. Using wired and $5 \mathrm{G}$ networks, they successfully completed a remote surgery experiment in two locations more than 3,000 miles apart. with the MRI environment; hence, designing a robot is challenging. A feasible solution is to place the power source outside the MRI operating room and transmit the power to the operating room through MRI-compatible mediums. For instance, Kwok et al. of the University of Hong Kong designed a hydraulic interventional EP robot (Figure 17A) $(59,68,69)$, and Abdelaziz et al. of Imperial College London designed a pneumatic interventional robot (Figure 17B) (70). The bodies and internal transmission parts of these robots were made of plastic or other materials compatible with the MRI environment.

\section{Prospects and conclusions}

At present, the vascular interventional surgical robotic system has mostly fulfilled the demand for remote manipulation of surgical instruments, and it is now moving in the direction of establishing stronger compatibility with interventional instruments and the application of more surgical functions. In scientific research, study of the mechanical structure and control methods of robots
A

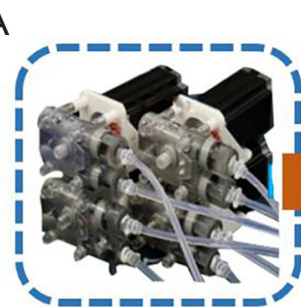

Hydraulic actuation units

B

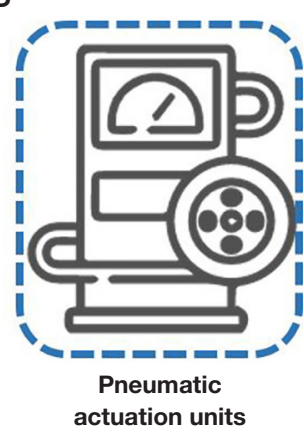

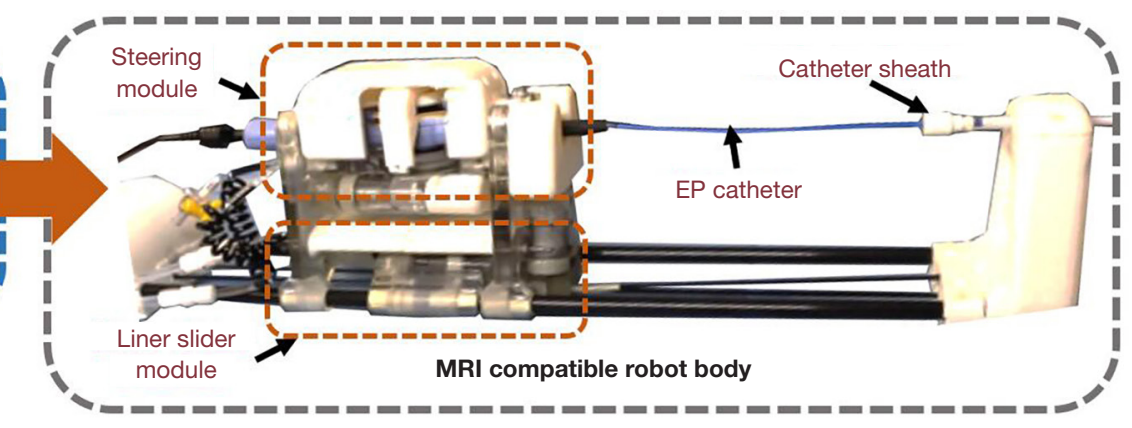

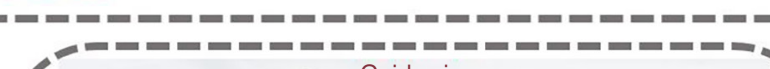

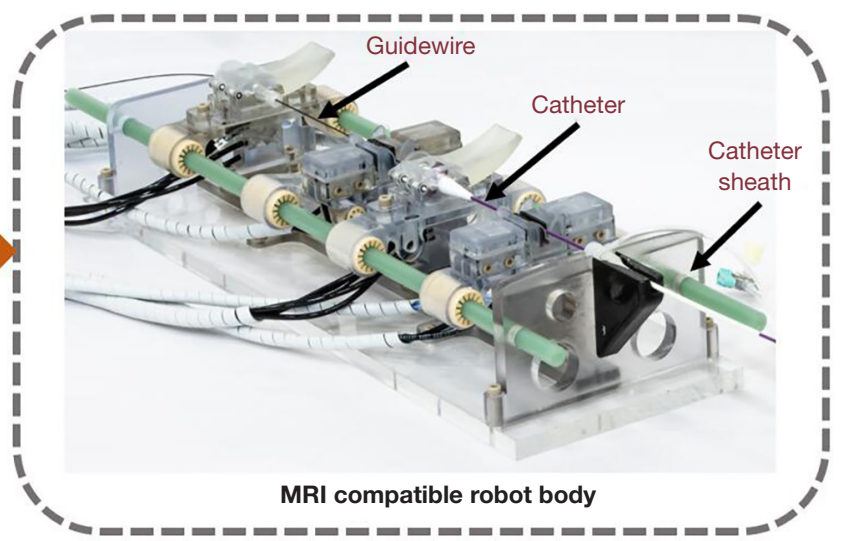

Figure 17 MRI-compatible interventional robots. (A) EP interventional robot designed by Kwok et al.; (B) general vasculature interventional robot designed by Abdelaziz et al. In this design, there are challenges in separating the actuator (with ferromagnetic and conductive materials) from the surgical robot and transferring the power through MRI-compatible mediums. MRI, magnetic resonance imaging; EP, electrophysiological. 
has gradually matured. Still, more in-depth research is needed in relation to haptic feedback, safety strategies, and autonomous delivery strategies. With continuous research and development, the vascular interventional surgical robotic system of the future is expected to be improved through integration of the following features:

(I) A more compatible robotic system for vascular interventional surgery. There are many surgical options for vascular intervention, for which the surgical instruments used differ. The future vascular interventional surgical robotic system will be compatible with more surgical instruments, with richer functions and corresponding modules enabling more surgical procedures and further reducing the need for manual operation by doctors.

(II) Richer sensor information. The addition of more relevant sensors during the design of the robotic system is important in allowing surgical status to be monitored in greater detail. The contact force between the surgical instrument and the blood vessel wall, the specific position and shape of the catheter and the guidewire, the shape and pressure of the blood vessel lumen, and other complex information have important guiding significance for a surgical robot system.

(III) More powerful master controllers. The hand perception of interventional doctors plays an important role in guiding the operations they perform, and the rich surgical experience of these doctors is also extremely important. Therefore, the more precise and reliable the haptic feedback and the more in line the design of the master manipulator is with the operating habits of interventional doctors, the easier it will be to use the robotic system and improve the surgical efficiency.

(IV) Robotic telestenting over long geographic distances. With the development of communication technology and the popularization of 5G Internet technology, remote surgery technology may be an important feature of surgical robot systems in the future. Remote surgery can alleviate the issue of uneven geographic distribution of interventional doctors. Experienced interventional doctors may perform interventional operations on patients remotely, from a long distance away.

(V) A training and teaching system for vascular interventional surgery robotics combined with virtual reality technology. Through virtual reality technology, blood vessel models, and interventional instruments, robotic mechanisms can be established in a virtual environment. Students can experience the simulated interventional surgery process and practice the operating methods of surgical robots with a master manipulator through accessing the virtual reality environment.

(VI) Extensive application of AI. With the accelerating development in AI in recent years, more and more AI methods will be applied to interventional surgical robot systems, such as medical image recognition, robotic sensor information analysis and safety warnings, and autonomous intelligent surgery.

Vascular interventional surgery robotics holds enormous potential. In the future, it will inevitably perform many tasks currently performed by interventional doctors in the operating room, reducing their workload and completing surgical goals more efficiently and safely.

Table 1 lists the research currently being conducted by vascular interventional surgical robots. 
Table 1 Studies of interventional surgical robots

\begin{tabular}{|c|c|c|c|c|}
\hline Research institution & Field & Haptics feedback & Force sensing & Autonomous delivery \\
\hline University of Hong Kong $(59,68,69)$ & EP & - & - & - \\
\hline Korea University (24) & EP & - & - & - \\
\hline Harbin Institute of Technology $(39,40)$ & EP & $\sqrt{ }$ & Proximal & - \\
\hline University of Waterloo (25) & EP & - & - & $\sqrt{ }$ \\
\hline Beijing University of Aeronautics and Astronautics $(34,77-81)$ & GV & $\sqrt{ }$ & Distal & - \\
\hline Yanshan University $(60,61,82-85)$ & GV & $\sqrt{ }$ & Proximal & - \\
\hline Tianjin University (86) & GV & & Distal & - \\
\hline Xiamen University (35) & GV & - & Proximal & - \\
\hline Saitama Institute of Technology (90) & GV & $\sqrt{ }$ & Proximal & - \\
\hline University of Illinois Urbana Champaign $(37,38)$ & GV & $\sqrt{ }$ & Proximal & - \\
\hline $\begin{array}{l}\text { Shenzhen Institutes of Advanced Technology, Chinese Academy of } \\
\text { Sciences }(32,91,92)\end{array}$ & GV & $\sqrt{ }$ & Proximal, distal & $\sqrt{ }$ \\
\hline Institute of Automation, Chinese Academy of Sciences $(17,44,93,94)$ & GV & $\sqrt{ }$ & - & $\sqrt{ }$ \\
\hline Hanyang University (95-98) & GV & $\sqrt{ }$ & Proximal & \\
\hline Imperial College London $(33,53,64,70,99-104)$ & GV & $\sqrt{ }$ & Distal & $\sqrt{ }$ \\
\hline Harbin Engineering University (113) & GV & - & - & - \\
\hline
\end{tabular}

EP, electrophysiological; GV, general vasculature.

\section{Acknowledgments}

Funding: This work was financially supported by the Project of Youth Innovation Fund of Xiamen City (No. 3502Z20206041), the Fundamental Research Funds for the Central Universities (No. 20720190144), the National Natural Science Foundation of China (No. 52075464), Science and Technology Program of Shenzhen City (No. JCYJ20180306172700388). and the Science and Technology Project of Xiamen Municipal Bureau of Science and Technology (No. 3502Z20194044).

\section{Footnote}

Reporting Checklist: The authors have completed the Narrative Review reporting checklist. Available at https:// qims.amegroups.com/article/view/10.21037/qims-21-792/rc

Conflicts of Interest: All authors have completed the ICMJE uniform disclosure form (available at https://qims. amegroups.com/article/view/10.21037/qims-21-792/ coif). GL serves as an unpaid editorial board member of Quantitative Imaging in Medicine and Surgery. The other 
authors have no conflicts of interest to declare.

Ethical Statement: The authors are accountable for all aspects of the work in ensuring that questions related to the accuracy or integrity of any part of the work are appropriately investigated and resolved.

Open Access Statement: This is an Open Access article distributed in accordance with the Creative Commons Attribution-NonCommercial-NoDerivs 4.0 International License (CC BY-NC-ND 4.0), which permits the noncommercial replication and distribution of the article with the strict proviso that no changes or edits are made and the original work is properly cited (including links to both the formal publication through the relevant DOI and the license). See: https://creativecommons.org/licenses/by-nc-nd/4.0/.

\section{References}

1. Miller DL. Overview of contemporary interventional fluoroscopy procedures. Health Phys 2008;95:638-44.

2. Miller DL, Vañó E, Bartal G, Balter S, Dixon R, Padovani R, Schueler B, Cardella JF, de Baère T; Society of Interventional Radiology. Occupational radiation protection in interventional radiology: a joint guideline of the Cardiovascular and Interventional Radiology Society of Europe and the Society of Interventional Radiology. Cardiovasc Intervent Radiol 2010;33:230-9.

3. Ross AM, Segal J, Borenstein D, Jenkins E, Cho S. Prevalence of spinal disc disease among interventional cardiologists. Am J Cardiol 1997;79:68-70.

4. Rafii-Tari H, Payne CJ, Yang GZ. Current and emerging robot-assisted endovascular catheterization technologies: a review. Ann Biomed Eng 2014;42:697-715.

5. Abdullah O, Omran J, Enezate T, Mahmud E, Shammas N, Mustapha J, Saab F, Abu-Fadel M, Ghadban R, Alpert M, Al-Dadah A. Percutaneous angioplasty versus atherectomy for treatment of symptomatic infra-popliteal arterial disease. Cardiovasc Revasc Med 2018;19:423-8.

6. Mukai M, Miyazaki S, Hasegawa K, Ishikawa E, Aoyama D, Nodera M, Kaseno K, Miyahara K, Matsui A, Shiomi Y, Tama N, Ikeda H, Fukuoka Y, Ishida K, Uzui H, Tada H. Cryothermal atrial linear ablation in patients with atrial fibrillation: An insight from the comparison with radiofrequency atrial linear ablation. J Cardiovasc Electrophysiol 2020;31:1075-82.

7. Matsuoka T, Okuma T. CT-guided radiofrequency ablation for lung cancer. Int J Clin Oncol 2007;12:71-8.
8. Won JY, Yi BJ, Cha HJ. Review of New Master/Slave Catheter Driving Vascular Intervention Robot System: Intervention Radiologist's Perspective. Hanyang Med Rev 2016;36:225-9.

9. Madder RD, VanOosterhout S, Mulder A, Elmore M, Campbell J, Borgman A, Parker J, Wohns D. Impact of robotics and a suspended lead suit on physician radiation exposure during percutaneous coronary intervention. Cardiovasc Revasc Med 2017;18:190-6.

10. Green BN, Johnson CD, Adams A. Writing narrative literature reviews for peer-reviewed journals: secrets of the trade. J Chiropr Med 2006;5:101-17.

11. Guo S, Yamaji H, Kita Y, Izuishi K, Tamiya T, editors. A novel active catheter system for ileus treatment. Qingdao, China: 2008 IEEE International Conference on Automation and Logistics, 2008.

12. Guo J, Guo S, Xiao N, Ma X, Yoshida S, Tamiya T, Kawanishi M. A novel robotic catheter system with force and visual feedback for vascular interventional surgery. Int J Mechatronics Automation 2012;2:15-24.

13. Bao X, Guo S, Xiao N, Li Y, Yang C, Shen R, Cui J, Jiang Y, Liu X, Liu K. Operation evaluation in-human of a novel remote-controlled vascular interventional robot. Biomed Microdevices 2018;20:34.

14. Bao X, Guo S, Xiao N, Li Y, Yang C, Jiang Y. A cooperation of catheters and guidewires-based novel remote-controlled vascular interventional robot. Biomed Microdevices 2018;20:20.

15. China's first interventional robot-assisted DSA operation completed in Tiantan Hospital. Care Health 2020;3:96.

16. Lu Q, Shen Y, Xia S, Chen B, Wang K. A Novel Universal Endovascular Robot for Peripheral Arterial StentAssisted Angioplasty: Initial Experimental Results. Vasc Endovascular Surg 2020;54:598-604.

17. Bian GB, Xie XL, Feng ZQ, Hou ZG, Wei P, Cheng L, Tan $M$, editors. An enhanced dual-finger robotic Hand for Catheter manipulating in vascular intervention: A preliminary study. Yinchuan, China: 2013 IEEE International Conference on Information and Automation (ICIA), 2013.

18. Medical H. Sensei® X Robotic System 2015 [cited 2018 Jun. 15]. Available online: http://www.hansenmedical.com/ us/en/cardiacarrhythmia

19. Beyar R, Gruberg L, Deleanu D, Roguin A, Almagor Y, Cohen S, Kumar G, Wenderow T. Remote-control percutaneous coronary interventions: concept, validation, and first-in-humans pilot clinical trial. J Am Coll Cardiol 2006;47:296-300. 
20. Robocath. The Medical Robot R-One 2019 [cited 2021 Jun. 30]. Available online: https://www.robocath.com/ product/

21. Cercenelli L, Bortolani B, Marcelli E. CathROB: A Highly Compact and Versatile Remote Catheter Navigation System. Appl Bionics Biomech 2017;2017:2712453.

22. Marcelli E, Cercenelli L, Plicchi G, editors. A novel telerobotic system to remotely navigate standard electrophysiology catheters. Bologna, Italy: 2008 Computers in Cardiology, 2008.

23. Cercenelli L, Marcelli E, Plicchi G. Initial experience with a telerobotic system to remotely navigate and automatically reposition standard steerable EP catheters. ASAIO J 2007;53:523-9.

24. Park JW, Choi J, Pak HN, Song SJ, Lee JC, Park Y, Shin SM, Sun K. Development of a force-reflecting robotic platform for cardiac catheter navigation. Artif Organs 2010;34:1034-9.

25. Ganji Y, Janabi-Sharifi F, Cheema AN. Robot-assisted catheter manipulation for intracardiac navigation. Int J Comput Assist Radiol Surg 2009;4:307-15.

26. Heunis C, Sikorski J, Misra S. Flexible instruments for endovascular interventions: Improved magnetic steering, actuation, and image-guided surgical instruments. IEEE Robot Autom Mag 2018;25:71-82.

27. Stereotaxis. The Genesis RMN System. 2020 [cited 2021 Jun. 30]. Available online: https://www.stereotaxis.com/ products/

28. Guo J, Guo S, Yu Y. Design and characteristics evaluation of a novel teleoperated robotic catheterization system with force feedback for vascular interventional surgery. Biomed Microdevices 2016;18:76.

29. Guo S, Song Y, Yin X, Zhang L, Tamiya T, Hirata H, Ishihara H. A Novel Robot-Assisted Endovascular Catheterization System With Haptic Force Feedback. IEEE Trans Robot 2019;35:685-96.

30. Guo J, Guo S, Wang P, Wei W, Wang Y, editors. A novel type of catheter sidewall tactile sensor array for vascular interventional surgery. Beijing, China: 2013 ICME International Conference on Complex Medical Engineering, 2013.

31. Guo J, Xiao N, Guo S, Tamiya T, editors. A force display method for a novel catheter operating system. Harbin, Heilongjiang, China: The 2010 IEEE International Conference on Information and Automation, 2010.

32. Omisore OM, Han SP, Ren LX, Wang GS, Ou FL, Li H, Wang L. Towards Characterization and Adaptive Compensation of Backlash in a Novel Robotic Catheter
System for Cardiovascular Interventions. IEEE Trans Biomed Circuits Syst 2018;12:824-38.

33. Payne CJ, Rafii-Tari H, Yang GZ, editors. A force feedback system for endovascular catheterisation. Vilamoura, Algarve: 2012 IEEE/RSJ International Conference on Intelligent Robots and Systems, 2012.

34. Zhao D, Liu D. Fuzzy fusion of forces feedback in vascular interventional surgery robot system. Robot 2013;35:60-6.

35. Zhou J, Mei Z, Miao J, Mao J, Wang L, Wu D, Sun D, Zhao Y. A Remote-Controlled Robotic System with Safety Protection Strategy Based on Force-Sensing and Bending Feedback for Transcatheter Arterial Chemoembolization. Micromachines (Basel) 2020;11:805.

36. Cha HJ, Yi BJ, Won JY. An assembly-type masterslave catheter and guidewire driving system for vascular intervention. Proc Inst Mech Eng H 2017;231:69-79.

37. Sankaran NK, Chembrammel P, Kesavadas T. Force calibration for an endovascular robotic system with proximal force measurement. Int J Med Robot 2020;16:e2045.

38. Sankaran NK, Chembrammel P, Siddiqui A, Snyder K, Kesavadas T. Design and Development of Surgeon Augmented Endovascular Robotic System. IEEE Trans Biomed Eng 2018;65:2483-93.

39. Fu Y, Gao A, Liu H, Li K, Liang Z, editors. Development of a novel robotic catheter system for endovascular minimally invasive surgery. Harbin, Heilongjiang, China: The 2011 IEEE/ICME International Conference on Complex Medical Engineering, 2011.

40. Fu Y, Gao A, Liu H, Guo S. The master-slave catheterisation system for positioning the steerable catheter. Int J Mechatronics Automation 2011;1:143-52.

41. Arai F, Fujimura R, Fukuda T, Negoro M, editors. New catheter driving method using linear stepping mechanism for intravascular neurosurgery. Wasington, DC, USA: Proceedings 2002 IEEE International Conference on Robotics and Automation (Cat No 02CH37292), 2002.

42. Tanimoto M, Arai F, Fukuda T, Itoigawa K, Hashimoto M, Takahashi I, Negoro M, editors. Telesurgery system for intravascular neurosurgery. Pittsburgh, PA, USA: International Conference on Medical Image Computing and Computer-Assisted Intervention, 2000: Springer.

43. Feng ZQ, Bian GB, Xie XL, Hou ZG, Hao JL, editors. Design and evaluation of a bio-inspired robotic hand for percutaneous coronary intervention. Seattle, Washington: 2015 IEEE International Conference on Robotics and Automation (ICRA), 2015.

44. Wang K, Liu J, Yan W, Lu Q, Nie S. Force feedback 
controls of multi-gripper robotic endovascular intervention: design, prototype, and experiments. Int J Comput Assist Radiol Surg 2021;16:179-92.

45. Wang K, Mai X, Xu H, Lu Q, Yan W. A novel SEAbased haptic force feedback master hand controller for robotic endovascular intervention system. Int J Med Robot 2020;16:1-10.

46. Xiao N, Guo P, Guo S, editors. Push force feedback for a kind of robotic catheter navigation system. Lijiang, Yunnan: 2015 IEEE International Conference on Information and Automation, 2015.

47. Thakur Y, Bax JS, Holdsworth DW, Drangova M. Design and performance evaluation of a remote catheter navigation system. IEEE Trans Biomed Eng 2009;56:1901-8.

48. Shi P, Guo S, Jin X, Song D, editors. A Two-channel Haptic Force Interface for Endovascular Robotic Systems. Beijing, China: 2020 IEEE International Conference on Mechatronics and Automation (ICMA), 2020.

49. Zheng L, Guo S. A magnetorheological fluid-based tremor reduction method for robot-assisted catheter operating system. Int J Mechatronics Automation 2021;8:72-9.

50. Yin X, Guo S, Xiao N, Tamiya T, Hirata H, Ishihara H. Safety operation consciousness realization of a MR fluidsbased novel haptic interface for teleoperated catheter minimally invasive neurosurgery. IEEE ASME Trans Mechatron 2015;21:1043-54.

51. Wang Y, Guo S, Zhao Y, Cui J, Ma Y, editors. A CNNsbased of force and torque identification model for vascular interventional surgery robot. Tianjin, China: 2019 IEEE International Conference on Mechatronics and Automation (ICMA), 2019.

52. Dagnino G, Liu J, Abdelaziz ME, Chi W, Riga C, Yang GZ, editors. Haptic feedback and dynamic active constraints for robot-assisted endovascular catheterization. Madrid, Spain: 2018 IEEE/RSJ International Conference on Intelligent Robots and Systems (IROS), 2018.

53. Shen H, Wang C, Xie L, Zhou S, Gu L, Xie H. A novel remote-controlled robotic system for cerebrovascular intervention. Int J Med Robot 2018;14:e1943.

54. Xiang Y, Shen H, Xie L, Wang H, editors. MasterSlave Guidewire and Catheter Robotic System for Cardiovascular Intervention. New Delhi, India: 28th IEEE International Conference on Robot and Human Interactive Communication (RO-MAN), 2019.

55. Guo S, Zhang L, Yang C, Shen R, editors. Recognition and Filtering of Tremor Signals for Vascular Interventional Surgical Robot. Beijing, China: 2020 IEEE International
Conference on Mechatronics and Automation (ICMA), 2020.

56. Yang C, Guo S, editors. A Novel Misoperation Preventing Device for the Interventional Surgical Robot. Beijing, China: 2020 IEEE International Conference on Mechatronics and Automation (ICMA), 2020.

57. Shen H, Wang C, Xie L, Zhou S, Gu L, Xie H. A novel robotic system for vascular intervention: principles, performances, and applications. Int J Comput Assist Radiol Surg 2019;14:671-83.

58. Jayender J, Patel RV, Nikumb S. Robot-assisted active catheter insertion: Algorithms and experiments. Int J Rob Res 2009;28:1101-17.

59. Wang X, Lee KH, Fu DKC, Dong Z, Wang K, Fang G, Lee SL, Lee APW, Kwok KW. Experimental validation of robot-assisted cardiovascular catheterization: model-based versus model-free control. Int J Comput Assist Radiol Surg 2018;13:797-804.

60. Yu H, Wang H, Chang J, Niu J, Wang F, Yan Y, Tian H, Fang J, Lu H. A Novel Vascular Intervention Surgical Robot Based on Force Feedback and Flexible Clamping. Applied Sciences 2021;11:611.

61. Wang H, Wang S, Zhang W, Xie L, Yang X, Vladareanu L, Munteanu R, editors. Fuzzy controller design of the wire feeder of invasive vascular interventional surgery robot. Beijing, China: 2015 International Conference on Advanced Mechatronic Systems (ICAMechS), 2015.

62. Jayender J, Azizian M, Patel RV. Autonomous imageguided robot-assisted active catheter insertion. IEEE Trans Robot 2008;24:858-71.

63. Al Nooryani A, Aboushokka W. Rotate-on-Retract Procedural Automation for Robotic-Assisted Percutaneous Coronary Intervention: First Clinical Experience. Case Rep Cardiol 2018;2018:6086034.

64. Chi W, Dagnino G, Kwok TM, Nguyen A, Kundrat D, Abdelaziz ME, Riga C, Bicknell C, Yang GZ, editors. Collaborative robot-assisted endovascular catheterization with generative adversarial imitation learning. Paris, France: 2020 IEEE International Conference on Robotics and Automation (ICRA), 2020.

65. Guo Y, Guo S, Yang C, editors. Feasibility Study on Cloud Communication Operation for an Interventional Surgery Robot. Beijing, China: 2020 IEEE International Conference on Mechatronics and Automation (ICMA), 2020.

66. Madder RD, VanOosterhout S, Mulder A, Bush J, Martin S, Rash A, Tan JM 2nd, Parker J, Li Y, Kottenstette N, Bergman P, Nowak B. Feasibility of robotic telestenting 
over long geographic distances: a pre-clinical ex vivo and in vivo study. EuroIntervention 2019;15:e510-2.

67. Madder RD, VanOosterhout S, Parker J, Sconzert K, Li Y, Kottenstette N, Madsen A, Sungur JM, Bergman P. Robotic telestenting performance in transcontinental and regional pre-clinical models. Catheter Cardiovasc Interv 2021;97:E327-32.

68. Dong Z, Guo Z, Lee KH, Fang G, Tang WL, Chang HC, Chan DTM, Kwok KW. High-Performance Continuous Hydraulic Motor for MR Safe Robotic Teleoperation. IEEE Robot Autom Lett 2019;4:1964-71.

69. Lee KH, Fu KCD, Guo Z, Dong Z, Leong MC, Cheung CL, Lee APW, Luk W, Kwok KW. MR safe robotic manipulator for MRI-guided intracardiac catheterization. IEEE ASME Trans Mechatron 2018;23:586-95.

70. Abdelaziz ME, Kundrat D, Pupillo M, Dagnino G, Kwok TM, Chi W, Groenhuis V, Siepel FJ, Riga C, Stramigioli $S$, editors. Toward a versatile robotic platform for fluoroscopy and MRI-guided endovascular interventions: A pre-clinical study. The Venetian Macao, Macau: 2019 IEEE/RSJ International Conference on Intelligent Robots and Systems (IROS), 2019.

71. Tavallaei MA, Gelman D, Lavdas MK, Skanes AC, Jones DL, Bax JS, Drangova M. Design, development and evaluation of a compact telerobotic catheter navigation system. Int J Med Robot 2016;12:442-52.

72. Tavallaei MA, Thakur Y, Haider S, Drangova M. A magnetic-resonance-imaging-compatible remote catheter navigation system. IEEE Trans Biomed Eng 2013;60:899-905.

73. Thakur Y, Jones DL, Skanes A, Yee R, Drangova M. Right-side RF ablation using remote catheter navigation: experimental results in vivo. J Cardiovasc Electrophysiol 2012;23:81-7.

74. Thakur Y, Holdsworth DW, Drangova M.

Characterization of catheter dynamics during percutaneous transluminal catheter procedures. IEEE Trans Biomed Eng 2009;56:2140-3.

75. Thakur Y, Cakiroglu JH, Holdsworth DW, Drangova M, editors. A device for real-time measurement of cathetermotion and input to a catheter navigation system. Medical Imaging 2007: Visualization and Image-Guided Procedures, 2007. International Society for Optics and Photonics.

76. Jayender J, Patel RV, Nikumb S, editors. Robot-assisted catheter insertion using hybrid impedance control. Orlando, Florida, USA: Proceedings 2006 IEEE International Conference on Robotics and Automation, 2006.
77. Meng C, Zhang J, Liu D, Liu B, Zhou F. A remotecontrolled vascular interventional robot: system structure and image guidance. Int J Med Robot 2013;9:230-9.

78. Tian ZM, Lu WS, Wang DM, Liu D, Zhang DP, Li ZC, Jia B. Experimental study of angiography using vascular interventional robot. Zhonghua Wai Ke Za Zhi 2010;48:1013-5.

79. Lu WS, Xu WY, Zhang J, Liu D, Wang DM, Jia P, Li ZC, Wang TM, Zhang DP, Tian ZM, Zeng Y. Application study of medical robots in vascular intervention. Int J Med Robot 2011;7:361-6.

80. Wang T, Zhang D, Da L. Remote-controlled vascular interventional surgery robot. Int J Med Robot 2010;6:194-201.

81. Guo J, Sun Y, Guo S, editors. A Novel Trajectory Predicting Method of Catheter for the Vascular Interventional Surgical Robot. Beijing, China: 2020 IEEE International Conference on Mechatronics and Automation (ICMA), 2020.

82. Wang H, Yang X, Hu G, Hou Z, Yu H, editors. Catheter intervention manipulation system of minimally invasive robotic surgery. Zhengzhou, China: The 2011 International Conference on Advanced Mechatronic Systems, 2011.

83. Yang X, Wang H, Yuan L, Du N, Hou Z, editors. Minimally invasive vascular interventional surgical robot system. Harbin, Heilongjiang, China: 2011 IEEE International Conference on Mechatronics and Automation, 2011.

84. Wang H, Tian H, Guo H, Yang X, Tian Y, Hu X, Chen $\mathrm{J}$, editors. Design of propulsion mechanism for vascular interventional operation robot. Zhengzhou, China: 2018 International Conference on Advanced Mechatronic Systems (ICAMechS), 2018.

85. Liu H, Wang H, Yang X, Jin Z, Wang Q, Li S, editors. Mechanism design of the minimally invasive vascular interventional surgery robot system. Ningbo, China: 2017 IEEE International Conference on Cybernetics and Intelligent Systems (CIS) and IEEE Conference on Robotics, Automation and Mechatronics (RAM), 2017.

86. He C, Wang S, Zuo S. A linear stepping endovascular intervention robot with variable stiffness and force sensing. Int J Comput Assist Radiol Surg 2018;13:671-82 .

87. Shen J, Li S, Chen D, Yan Y. Design and experiment of guide wire tele-manipulation system based on laser mouse sensor. Zhongguo Yi Liao Qi Xie Za Zhi 2012;36:32-5.

88. Wang K, Lu Q, Chen B, Shen Y, Li H, Liu M, Xu Z. Endovascular intervention robot with multi- 
manipulators for surgical procedures: Dexterity, adaptability, and practicability. Robot Comput Integr Manuf 2019;56:75-84.

89. Li L, Huang Z, Tian Y, Wang W, Chen W, Li Z, Xi F, editors. Design and Performance Evaluation of a Novel Vascular Interventional Surgery Robot. Kuala Lumpur, Malaysia: 2018 IEEE International Conference on Robotics and Biomimetics (ROBIO), 2018.

90. Zakaria NAC, Komeda T, Low CY, Makoto M, Kobayashi M, Ismail AY, Dumitrescu R. Development of foolproof catheter guide system based on mechatronic design. Production Engineering 2013;7:81-90.

91. Omisore OM, ShiPeng H, LingXue R, Lei W, editors. A teleoperated robotic catheter system with motion and force feedback for vascular surgery. Korea: 2018 18th International Conference on Control, Automation and Systems (ICCAS), 2018.

92. Mi J, He Y, Zhang P, Hu Y, Wu J, Zhang J, editors. A vascular intervention assisted robot based on master-slave control mode. Tianjin, China: 2014 IEEE International Conference on Mechatronics and Automation, 2014.

93. Ji C, Hou ZG, Xie XL, editors. Guidewire navigation and delivery system for robot-assisted cardiology interventions. Banff, Canada: IEEE 10th International Conference on Cognitive Informatics and Cognitive Computing (ICCICC'11), 2011.

94. Huang RJ, Bian GB, Xin C, Li Z, Hou ZG, editors. Path planning for surgery robot with bidirectional continuous tree search and neural network. Venetian Macao, Macau: 2019 IEEE/RSJ International Conference on Intelligent Robots and Systems (IROS), 2019.

95. Lee W, Nam J, Kim J, Jung E, Kim N, Jang G. Steering, Tunneling, and Stent Delivery of a Multifunctional Magnetic Catheter Robot to Treat Occlusive Vascular Disease. IEEE Trans Industr Electron 2020;68:391-400.

96. Woo J, Song HS, Cha HJ, Yi BJ. Advantage of steerable catheter and haptic feedback for a 5-DOF vascular intervention robot system. Applied Sciences 2019;9:4305.

97. Cha HJ, Yoon HS, Jung K, Yi BJ, Lee S, Won J, editors. A robotic system for percutaneous coronary intervention equipped with a steerable catheter and force feedback function. Daejeon, Korea: 2016 IEEE/ RSJ International Conference on Intelligent Robots and Systems (IROS), 2016.

98. Cha HJ, Yi BJ, editors. Design concept of a micro robot delivery system. Goyang, Korea: 2015 12th International Conference on Ubiquitous Robots and Ambient Intelligence (URAI), 2015.
99. Rafii-Tari H, Payne CJ, Bicknell C, Kwok KW, Cheshire NJW, Riga C, Yang GZ. Objective Assessment of Endovascular Navigation Skills with Force Sensing. Ann Biomed Eng 2017;45:1315-27.

100. Rafii-Tari H, Payne CJ, Liu J, Riga C, Bicknell C, Yang GZ, editors. Towards automated surgical skill evaluation of endovascular catheterization tasks based on force and motion signatures. Seattle, Washington: 2015 IEEE International Conference on Robotics and Automation (ICRA), 2015.

101.Rafii-Tari H, Liu J, Lee SL, Bicknell C, Yang GZ. Learning-based modeling of endovascular navigation for collaborative robotic catheterization. Med Image Comput Comput Assist Interv 2013;16:369-77.

102. Chi W, Liu J, Rafii-Tari H, Riga C, Bicknell C, Yang GZ. Learning-based endovascular navigation through the use of non-rigid registration for collaborative robotic catheterization. Int J Comput Assist Radiol Surg 2018;13:855-64.

103. Chi W, Liu J, Abdelaziz ME, Dagnino G, Riga C, Bicknell C, Yang GZ, editors. Trajectory optimization of robot-assisted endovascular catheterization with reinforcement learning. Madrid, Spain: 2018 IEEE/RSJ International Conference on Intelligent Robots and Systems (IROS), 2018.

104.Molinero MB, Dagnino G, Liu J, Chi W, Abdelaziz ME, Kwok TM, Riga C, Yang GZ, editors. Haptic guidance for robot-assisted endovascular procedures: implementation and evaluation on surgical simulator. The Venetian Macao, Macau: 2019 IEEE/RSJ International Conference on Intelligent Robots and Systems (IROS), 2019.

105.Zhou W, Guo S, Chen Z, editors. A Novel Axial Force Feedback Device for the Master Manipulator of the Vascular Interventional Surgical Robot. Beijing, China: 2020 IEEE International Conference on Mechatronics and Automation (ICMA), 2020.

106.Zhao Y, Guo S, Wang Y, Cui J, Ma Y, Zeng Y, Liu X, Jiang Y, Li Y, Shi L, Xiao N. A CNN-based prototype method of unstructured surgical state perception and navigation for an endovascular surgery robot. Med Biol Eng Comput 2019;57:1875-87.

107.Zhao Y, Xing H, Guo S, Wang Y, Cui J, Ma Y, Liu Y, Liu $\mathrm{X}$, Feng J, Li Y. A novel noncontact detection method of surgeon's operation for a master-slave endovascular surgery robot. Med Biol Eng Comput 2020;58:871-85. 108. Tercero C, Ikeda S, Uchiyama T, Fukuda T, Arai F, Okada Y, Ono Y, Hattori R, Yamamoto T, Negoro M, Takahashi I. Autonomous catheter insertion system using magnetic motion capture sensor for endovascular surgery. Int J Med 
Robot 2007;3:52-8.

109. Tanimoto M, Arai F, Fukuda T, Iwata H, Itoigawa K,

Gotoh Y, Hashimoto M, Negoro M, editors. Micro

force sensor for intravascular neurosurgery and in vivo experiment. An Investigation of Micro Structures, Sensors, Actuators, Machines and Systems (Cat No 98CH36176).

Heidelberg, Germany. Piscataway, NJ: Proceedings MEMS 98 IEEE Eleventh Annual International Workshop on Micro Electro Mechanical Systems, 1998.

110. Guo S, Fukuda T, Kosuge K, Arai F, Oguro K, Negoro $\mathrm{M}$, editors. Micro catheter system with active guide wire. Nagoya, Aichi, Japan: Proceedings of 1995 IEEE International Conference on Robotics and Automation, 1995. 111. Srimathveeravalli G, Kesavadas T, Li X. Design and

Cite this article as: Zhao Y, Mei Z, Luo X, Mao J, Zhao Q, Liu G, Wu D. Remote vascular interventional surgery robotics: a literature review. Quant Imaging Med Surg 2022;12(4):25522574. doi: 10.21037/qims-21-792 fabrication of a robotic mechanism for remote steering and positioning of interventional devices. Int $\mathrm{J}$ Med Robot 2010;6:160-70.

112. Rosa B, Devreker A, De Praetere H, Gruijthuijsen C, Portoles-Diez S, Gijbels A, Reynaerts D, Herijgers P, Vander Sloten J, Vander Poorten E, editors. Intuitive teleoperation of active catheters for endovascular surgery. Hamburg, Germany: 2015 IEEE/RSJ International Conference on Intelligent Robots and Systems (IROS), 2015.

113. Feng W, Chi C, Wang H, Wang K, Guo S, editors. Highly precise catheter driving mechanism for intravascular neurosurgery. Luoyang, China: 2006 International Conference on Mechatronics and Automation, 2006. 